\title{
Interaction of the $\mathrm{H}$-cluster of FeFe hydrogenase with halides
}

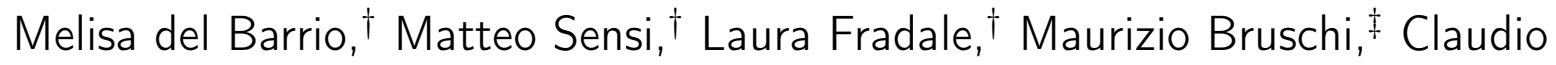

Greco ${ }^{\ddagger}$ Luca de Gioia, $₫$ Luca Bertini, ${ }^{*} \uparrow$ Vincent Fourmond, ${ }^{\dagger}$ and Christophe

$$
\text { Léger*,† }
$$

$\dagger$ †ix Marseille Univ., CNRS, Bioénergétique et Ingénierie des Protéines, Marseille, France. $\ddagger$ Department of Earth and Environmental Science, Univ. of Milano Bicocca, Milan, Italy. IDepartment of Biotechnologies and Biosciences, Univ. of Milano-Bicocca, Milan, Italy

E-mail: luca.bertini@unimib.it; leger@imm.cnrs.fr

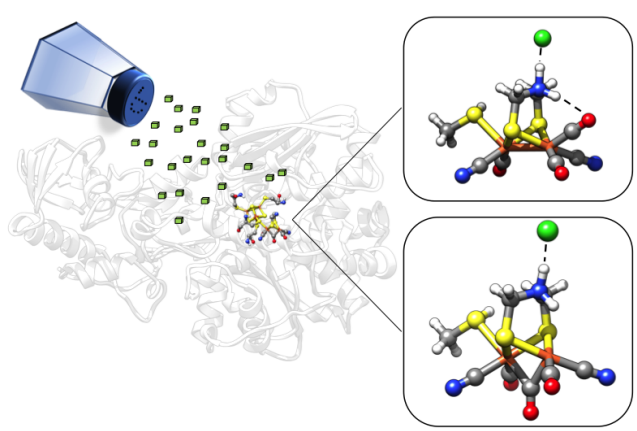

\begin{abstract}
FeFe hydrogenases catalyse $\mathrm{H}_{2}$ oxidation and production using a "H-cluster", where two Fe ions are bound by an aza-dithiolate (adt) ligand. Various hypotheses have been proposed (by us and others) to explain that the enzyme reversibly inactivates under oxidizing, anaerobic conditions: intramolecular binding of the $\mathrm{N}$ atom of adt, formation of the so-called "Hox/inact" state or non-productive binding of $\mathrm{H}_{2}$ to isomers of
\end{abstract}


Author version of: J. Am. Chem. Soc. 1405485 (2018)

http://dx.doi.org/doi:10.1021/jacs.8b01414

the H-cluster. Here we show that none of the above explains the new finding that the anaerobic, oxidative, $\mathrm{H}_{2}$-dependent reversible inactivation is strictly dependent on the presence of $\mathrm{Cl}^{-}$or $\mathrm{Br}^{-}$. We provide experimental evidence that chloride uncompetitively inhibits the enzyme: it reversibly binds to catalytic intermediates of $\mathrm{H}_{2}$ oxidation (but not to the resting "Hox" state), after which oxidation locks the active site into a stable, saturated, inactive form, the structure of which is proposed here based on DFT calculations. The halides interact with the amine group of the H-cluster but do not directly bind to iron. It should be possible to stabilize the inhibited state in amounts compatible with spectroscopic investigations to explore further this unexpected reactivity of the H-cluster of hydrogenase.

\section{Introduction}

Hydrogenases are the enzymes that oxidize and produce $\mathrm{H}_{2} \cdot{ }^{1]}$ The so-called "FeFe" hydrogenases do so at an inorganic active site, the H-cluster, which consists of a $\mathrm{Fe}_{4} \mathrm{~S}_{4}$ cluster bound by a cysteine to a $\mathrm{Fe}_{2}$ subsite. The two iron atoms are called "proximal" or "distal" depending on their position relative to the cubane. They are coordinated by a carbonyl and a cyanide ligands and bridged by a third carbonyl and an azadithiolate (adt) group (fig 11. After $\mathrm{H}_{2}$ binding to the distal $\mathrm{Fe}\left(\mathrm{Fe}_{d}\right)$, the first step of $\mathrm{H}_{2}$ oxidation is the heterolytic splitting of $\mathrm{H}_{2}$ to form a terminal hydride ${ }^{2 \mid 3}$ and a proton; the latter is transferred to the nitrogen atom of adt. 4

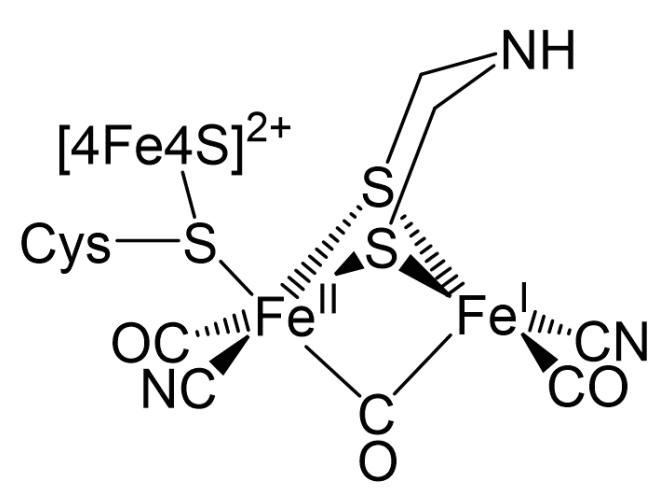

Figure 1: The H-cluster of FeFe hydrogenase in the so-called "Hox" state, before $\mathrm{H}_{2}$ binds. The redox state assignment shown here agrees with some $\operatorname{IR}^{516}$ $\mathrm{EPR}^{[78}$ and DFT investigations ${ }^{9 / 10}$ but contrasts with the conclusions from other investigations using HYSCORE ${ }^{11}$ and FTIR. ${ }^{12}$ 
FeFe hydrogenases oxidize and produce $\mathrm{H}_{2}$ at very high rate, but they inactivate more or less reversibly under various conditions: $: \frac{13}{13}$ in the presence of the inhibitors $\left.\mathrm{CO}, 14-16\right], \frac{16}{2}, \frac{17-20}{20}$ $\mathrm{H}_{2},{ }^{21}$ upon irradiation, ${ }^{19222}$ at low potential ${ }^{2324}$ or at high potential either in the absence ${ }^{\sqrt{25}}$ or presence ${ }^{26127}$ of $\mathrm{H}_{2}$. The reactivity of the H-cluster is indeed very diverse.

Here we focus on oxidative inactivation in the presence of $\mathrm{H}_{2}$. This reaction is easily detected $^{26}$ in protein film voltammetry experiments such as those shown in fig 2 , In this technique, a small amount of enzyme is directly wired to an electrode, immersed in a solution that contains $\mathrm{H}_{2}$, and the change in $\mathrm{H}_{2}$-oxidation or $\mathrm{H}_{2}$-evolution activity is detected as a change in catalytic current as the potential is swept or stepped up and down. $\frac{1328}{128}$ The hysteresis at high potential in fig 2 is the signature of reversible, oxidative inactivation. Various hypotheses have been put forward to explain this phenomenon, none of which is consistent with the new evidence reported in this paper.

The high potential inactivation of FeFe hydrogenase was first observed in electrochemical experiments carried out with the enzyme from $D$. desulfuricans, ${ }^{26}$ suggesting that the inactivation results from the formation of the so-called $\mathrm{Hox}_{\text {inact }}$ state of the enzyme, which is obtained after aerobic purification of the FeFe hydrogenase from sulfate-reducing bacteria (this form, whose structure is unknown, is inactive, protected from $\mathrm{O}_{2}$ and transforms into an active state by reduction). However, the high potential inactivation was later observed

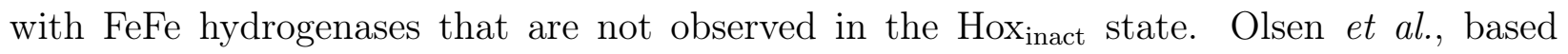
on the structure of a diferrous biomimetic complex, proposed that the inactivation of the enzyme results from the formation of an iron-nitrogen bond between the adt nitrogen and $\mathrm{Fe}_{d}$ upon oxidation of Hox. ${ }^{29}$ However, DFT calculations later suggested that the protein matrix around the $\mathrm{H}$-cluster prevents the formation of the $\mathrm{Fe}_{d}-\mathrm{N}$ (adt) bond. ${ }^{30}$ In a recent experimental investigation, we observed that the (in)activation is biphasic (showing that two inactive species are formed at high potential) and proceeds with a rate that is independent of potential and proportional to $\left[\mathrm{H}_{2}\right]$; we concluded that the inactivation results from the nonproductive binding of $\mathrm{H}_{2}$ to isomers of the $\mathrm{H}$-cluster where one of the distal $\mathrm{CO}$ has moved to 
an axial position, ${ }^{27}$ consistent with other experimental evidence according to which isomeri-

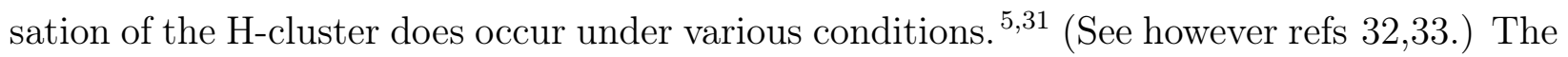
electrochemical data showed that the inactivation is a one-electron one-proton oxidation. 27

Here we report that the inactivation of FeFe hydrogenase is also strictly dependent on the presence of either chloride or bromide, ruling out earlier mechanistic hypotheses (including ours). We demonstrate that under oxidative conditions, chloride behaves as an uncompetitive inhibitor: it binds to a catalytic intermediate and favors over-oxidation into very stable form whose putative structure is calculated using DFT.

\section{Results}

\section{Qualitative observations of the effect of anions, including chloride and bromide}

Figure 2 $2 \mathrm{~A}$ shows, in red, a cyclic voltammogram recorded with the FeFe hydrogenase from C. reinhardtii $(\mathrm{Cr})$ adsorbed onto a rotating electrode, under an atmosphere of $\mathrm{H}_{2}$, in a buffer that contains a large concentration of chloride. The current changes from being negative $\left(\mathrm{H}_{2}\right.$ evolution) to positive $\left(\mathrm{H}_{2}\right.$ oxidation $)$ as the electrode potential increases. The current decreases as the potential is increased above $\approx 0 \mathrm{mV}$ vs SHE and increases again on the reverse scan when the potential becomes more negative. This is the signature of the anaerobic, oxidative, reversible inactivation, which results in a strong hysteresis because it is slow on the voltammetric time scale.

The new observation in fig $2 \mathrm{~A}$ is that the magnitude of the high potential inactivation is very dependent on the concentration of $\mathrm{NaCl}$. We observed the same effect of $\mathrm{NaCl}$ with the FeFe hydrogenase from C. acetobutylicum (SI fig S2). In contrast, $\mathrm{Cl}^{-}$has no effect on NiFe hydrogenase (SI fig S3). The inactivation of Cr FeFe hydrogenase is also observed after adding $\mathrm{KBr}$ to the solution (fig $2 \mathrm{~B}$ ), whereas $\mathrm{KNO}_{3}(0.5 \mathrm{M}) \mathrm{Na}_{2} \mathrm{SO}_{4}(0.1 \mathrm{M}), \mathrm{NaF}(0.3 \mathrm{M})$ and KI (0.5 M) have no effect (SI fig. S4). We conclude that the changes seen in fig 2 are caused by $\mathrm{Cl}^{-}$and $\mathrm{Br}^{-}$: other anions, cations and changes in ionic strength have no effect 
on the catalytic wave-shape.

$\mathrm{Cl}^{-}$and $\mathrm{Br}^{-}$have no other effect than changing the voltammetric wave-shape at high potential. Fig 2 shows that increasing the concentration of $\mathrm{Cl}^{-}$or $\mathrm{Br}^{-}$does not modify the low potential part of the signal ( $E<0 \mathrm{mV}$ vs SHE). SI figure S5 also shows that $\mathrm{Cl}^{-}$ does not modify the rates of the reactions with $\mathrm{O}_{2}$ or $\mathrm{CO}$. Since the latter depend on the rate of diffusion inside the protein, $\frac{18}{18}$ we conclude that halides do not significantly alter the dynamics of the protein.

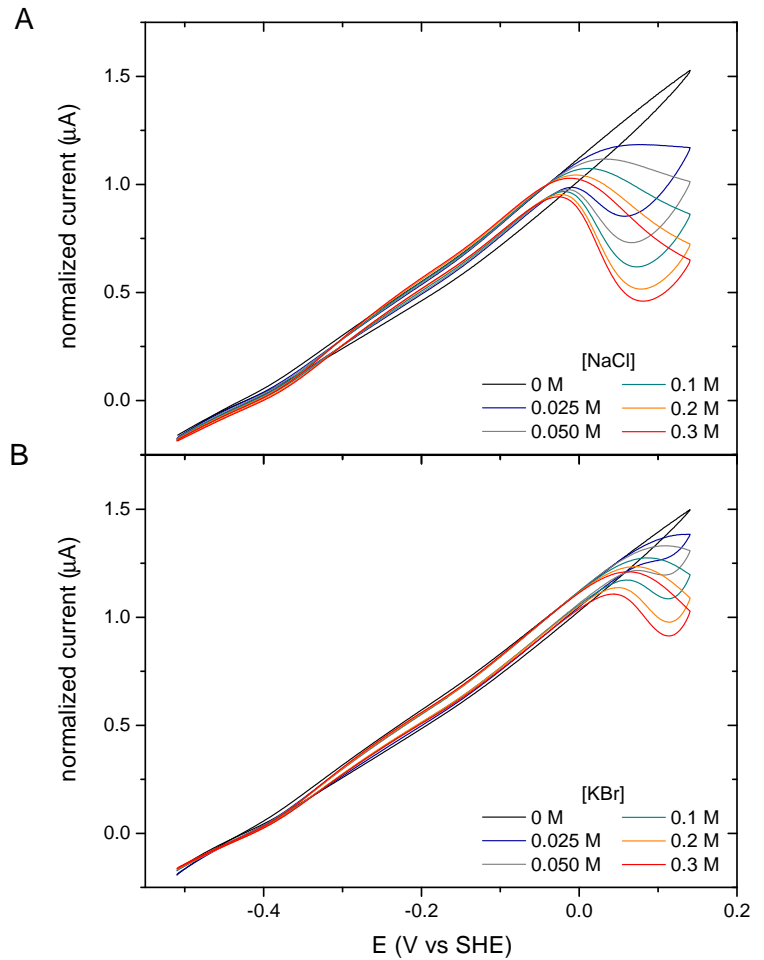

Figure 2: Effect of the concentration of chloride (panel A) and bromide (panel B), on the voltammetric response of C. reinhardtii $\mathrm{FeFe}$ hydrogenase adsorbed at a rotating disc graphite electrode. Experimental conditions: 1 bar $\mathrm{H}_{2}$, scan rate $\nu=20 \mathrm{mV} / \mathrm{s}$, rotation rate $\omega=3000 \mathrm{rpm}, T=2^{\circ} \mathrm{C}$, the concentration of halide was varied by adding a solution of $\mathrm{NaCl}$ or $\mathrm{KBr}$ to a $5 \mathrm{mM}$ mixed buffer solution at $\mathrm{pH} 7$.

\section{Reversible anaerobic inactivation is strictly dependent upon the presence of}

\section{$\mathrm{Cl}^{-}$or $\mathrm{Br}^{-}$}

To analyse the kinetics of the redox-driven inactivation, it is easier to interpret the results of chronoamperometry experiments than voltammograms. ${ }^{[27}$ Figure S6 shows a typical chronoamperometry experiment where the current increases and decreases each time the potential is stepped down or up, respectively. The conversion results in a hysteresis in fig 2 because it is slower than the voltammetric time scale $(\tau=R T / F \nu \approx 1 \mathrm{~s})$. 
As observed before, $\stackrel{27}{27}$ the changes in current are clearly biphasic, suggesting that two distinct inactive species are formed under oxidative conditions. The kinetic model that was fitted to the data ${ }^{27}$ assumes that the active form of the active site, $\mathrm{A}$, is transformed into two different species, I' and I", with first order rate constants $k_{i}^{\prime}$ and $k_{i}^{\prime \prime}$, and reactivates with first order rate constants $k_{a}^{\prime}$ and $k_{a}^{\prime \prime}$. No assumption is made on the dependence of the rate constants on potential.

We confirmed our previous observation that the two rate constants of inactivation are independent of potential and that the rate constants of reactivation increase as the electrode potential is lowered (fig 3 in ref [27, and SI figure S7). As before, we conclude that the inactivation follows a "CE" mechanism, whereby the inactivation begins with a reversible chemical step that limits the inactivation rate and is followed by an oxidation. Reactivation is triggered by the reduction of the inactive form.

An important, new information is that the values of the inactivation rate constants increase with chloride concentration, as shown in fig 3 , unlike the rate constants of reactivation (SI figure S7). Determining the values of $k_{i}$ at very low concentration of chloride is difficult because there the magnitude of the inactivation is very small but the data strongly suggest that both $k_{i}^{\prime}$ and $k_{i}^{\prime \prime}$ tend to zero as $\left[\mathrm{Cl}^{-}\right]$tends to zero; this is consistent with the qualitative observation that no inactivation is detected in the voltammograms recorded in the absence of $\mathrm{NaCl}$ (fig $2 \mathrm{~A})$.

\section{Evidence that $\mathrm{Cl}^{-}$acts as an uncompetitive inhibitor}

We showed in fig $3 \mathrm{~d}$ of ref 27 that the two values of $k_{i}$ increase with the concentration of $\mathrm{H}_{2}$. We interpreted this in terms of $\mathrm{H}_{2}$ binding being the "C" step of the $\mathrm{CE}$ mechanism of inactivation, but there is actually an alternative: $k_{i}$ may be the rate of binding of the inhibitor halide, which should increase with $\left[\mathrm{H}_{2}\right]$ if $\mathrm{Cl}^{-}$binds to a catalytic intermediate, whose steady-state concentration increases in proportion to the turnover rate.

Strong support of the hypothesis that $\mathrm{Cl}^{-}$binds to catalytic intermediates comes from the effect of chloride on the value of the Michaelis constant for $\mathrm{H}_{2}$ at high potential, which 


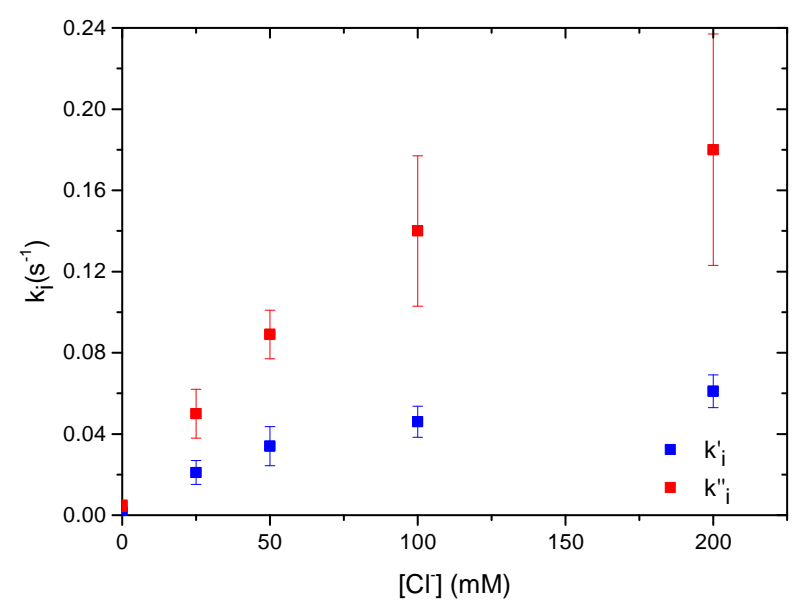

Figure 3: Dependence of the inactivation rate constants $k_{i}^{\prime}$ and $k_{i}^{\prime \prime}$ on chloride concentration. Experimental conditions: 1 bar $\mathrm{H}_{2}, \mathrm{~T}=2^{\circ} \mathrm{C}$, mixed buffer $\mathrm{pH} 7$.

reveals that chloride is an uncompetitive inhibitor ${ }^{34}$ of $\mathrm{H}_{2}$ oxidation at high potential. The Michaelis constant at a given potential and concentration of chloride can be measured by changing the concentration of $\mathrm{H}_{2}$ (e.g. as in fig $4 \mathrm{~A}$ ) and monitoring the change in current; figure $4 \mathrm{~B}$ shows a typical result at $E=115 \mathrm{mV}$ and $\left[\mathrm{Cl}^{-}\right]=0.1 \mathrm{M}$ (see SI fig S8 for the result at $\left.\left[\mathrm{Cl}^{-}\right]=0\right)$. The continuous current decay results from film loss and can be corrected ${ }^{35}$ as shown in the inset of panel $\mathrm{B}$. The details of the current response in figure $4 \mathrm{~B}$ confirm that $\mathrm{H}_{2}$ favors the inactivation. Indeed, each time the $\mathrm{H}_{2}$ concentration is stepped up, the activity increases as a consequence of enzyme saturation with $\mathrm{H}_{2}$ and then slowly decreases (as indicated by stars) because the enzyme slowly inactivates. Similarly, every step down in $\mathrm{H}_{2}$ concentration is followed by a fast decrease in current followed by a reactivation (squares in panel B). After each step in $\mathrm{H}_{2}$ concentration, the activity tends to a new steady-state value which is easily compared to that measured under one bar $\mathrm{H}_{2}$. The change in normalized current against $\left[\mathrm{H}_{2}\right]$ (panel $\mathrm{C}$ ) gives the value of the Michaelis constant at each concentration of chloride. The inset of panel $\mathrm{C}$ shows that the apparent value of $K_{m}$ changes with $\left[\mathrm{Cl}^{-}\right]$ according to

$$
K_{m}^{\mathrm{app}}\left(\left[\mathrm{Cl}^{-}\right]\right)=\frac{K_{m}\left(\left[\mathrm{Cl}^{-}\right]=0\right)}{1+\left[\mathrm{Cl}^{-}\right] / K_{i}(E)}
$$

as expected if chloride is an uncompetitive inhibitor. ${ }^{34}$ Eq. 1 allows $K_{i}$ to depend on $E$, since chloride inhibition is only observed at high electrode potential. Fitting a straight line 
to the data points in the inset of panel $\mathrm{C}$ returns $K_{i}=0.021 \mathrm{M} \mathrm{Cl}^{-}$at $E=115 \mathrm{mV}$, and $K_{m}\left(\left[\mathrm{Cl}^{-}\right]=0\right)=0.18 \mathrm{~atm} \mathrm{H}_{2}$, similar to the value found ${ }^{21}$ at low potential, where chloride has no effect.

\section{The kinetics of reactivation}

The reactivation rate constants $k_{a}^{\prime}$ and $k_{a}^{\prime \prime}$ increase exponentially as the electrode potential is lowered and depend on $\mathrm{pH}$ as expected if the reactivation is triggered by a one-electron reduction that is coupled to protonation. ${ }^{27}$ The values of $k_{a}$ are independent of the concentration of halide but they depend on its nature: this is clear from the observation in fig 2 that the potential where the activity "switches back on" on the sweep to low potential is independent of the concentration of halide, and it is $55 \mathrm{mV}$ higher with bromide than with chloride (75 mV vs SHE compared to $20 \mathrm{mV}$ ). Indeed, this "switch potential" directly depends on the rate of reactivation. ${ }^{36137}$ Since $k_{a}$ is proportional to $e^{-F E / R T}$, the $55 \mathrm{mV}$ shift of the reactivation potential when $\mathrm{Cl}^{-}$is replaced with $\mathrm{Br}^{-}$reveals a 10-fold increase in reactivation rate $\left(\right.$ at $\left.2^{\circ} \mathrm{C}\right)$.

That the rate of reaction of the inactive species is different in the presence of chloride or bromide suggests that the anion is bound very close to the H-cluster in the inactive form, consistent with the above conclusion that it binds to a catalytic intermediate.

The affinity of the H-cluster for halides The chronoampetrometry experiments give the values of $k_{a}$ and $k_{i}$, the ratio of which is related to the halide binding constant.

The value of $K_{i}(0.021 \mathrm{M})$ measured at $E=115 \mathrm{mV}$ from the data in fig. 4 compares well with that deduced from the values of the inactivation and reactivation rate constants obtained at this potential by chronoamperometry experiments. Indeed, from the data shown in fig. S7 at $\left[\mathrm{Cl}^{-}\right]=0.1 \mathrm{M}$, and given that $K_{i}=\left(k_{a}^{\prime} / k_{i}^{\prime}+k_{a}^{\prime \prime} / k_{i}^{\prime \prime}\right) \times\left[\mathrm{Cl}^{-}\right]$, we deduce $K_{i} \approx 0.023 \mathrm{M}$. From chronoamperometry experiments at $0.05 \mathrm{M} \mathrm{Cl}^{-}$, we obtained a similar value of $K_{i} \approx 0.014 \mathrm{M}$.

At low potential, no inactivation is observed because $k_{a} \gg k_{i}$. The ratio $k_{a} / k_{i}$ at the lowest potential where an inactivation is detected therefore gives a lower limit for the dis- 
A

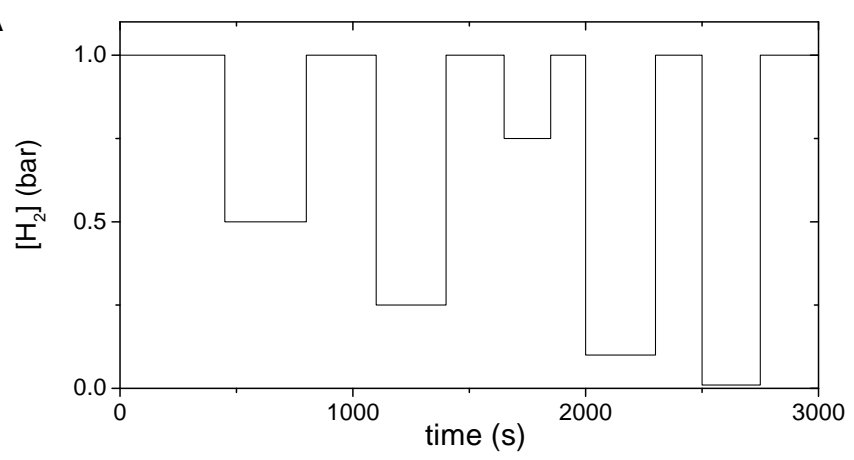

B

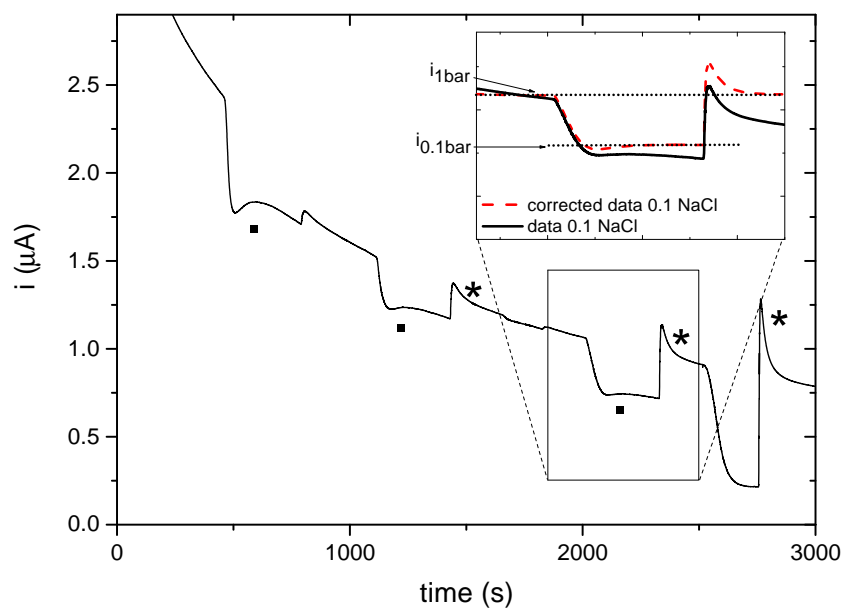

C

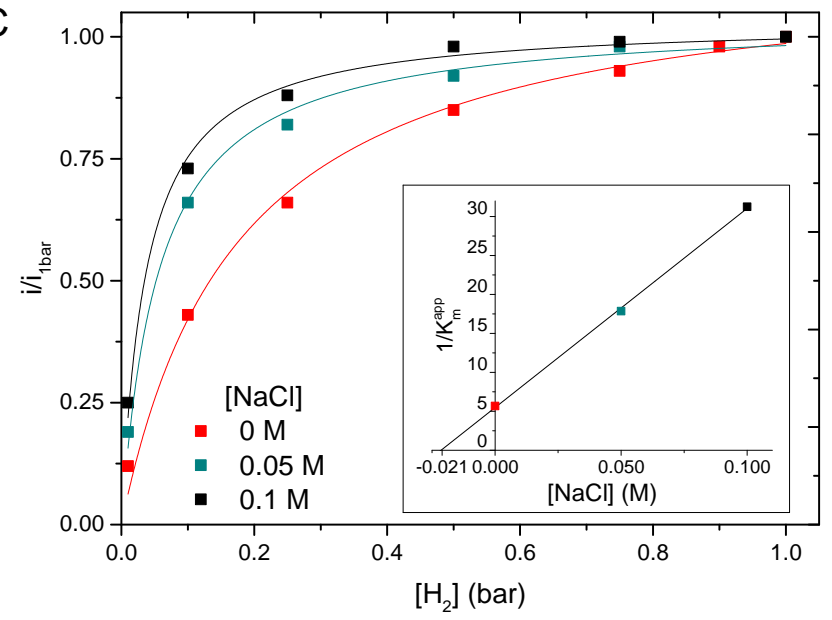

Figure 4: Chronoamperometric experiment and effect of chloride on $K_{m}$ at high potential. A: Concentration of $\mathrm{H}_{2}$ against time (note that the change occurs with a time constant of about $35 \mathrm{~s}$, it is therefore slower than depicted in panel $\mathrm{A}$; this prevents the quantitative interpretation of the current transients in panel B.) . B: Resulting current at $\left[\mathrm{Cl}^{-}\right]=0.1$ M (see SI fig S8 for same experiment at $\left.\left[\mathrm{Cl}^{-}\right]=0 \mathrm{M}\right)$, inset: current corrected from film loss (in red), raw current data (in black) and current values at 1 and 0.1 bar $\mathrm{H}_{2}$ (dotted lines) used for the calculation of the relative current $i_{0.1 \mathrm{bar}} / i_{1 \mathrm{bar}}$ plotted in panel C. C: Relative current $i / i_{1 \text { bar }}$ against $\left[\mathrm{H}_{2}\right]$, inset: $1 / K_{m}^{\text {app }}$ as a function of $\left[\mathrm{Cl}^{-}\right]$. Experimental conditions: $E=$ $115 \mathrm{mV}$, rotation rate $\omega=3000$ rpm, $T=2^{\circ} \mathrm{C}$, in mixed buffer $\mathrm{pH} 7$. 
sociation constant of $\mathrm{Cl}^{-}$. From the data in fig S7, we determine $K_{d} \gg 4 \mathrm{M}$, that is $\Delta_{r} G^{0}>1 \mathrm{kcal} / \mathrm{mol}$ for the binding of $\mathrm{Cl}^{-}$to the catalytic intermediate.

\section{Working hypothesis}

Based on the above described observations and on DFT calculations described below, we propose the inhibition mechanism shown in fig 5. Hox is the "resting" $\mathrm{Fe}(\mathrm{II}) \mathrm{Fe}(\mathrm{I})$ state of the active site, which accumulates under oxidizing conditions in the absence of $\mathrm{H}_{2}{ }^{25}$ and binds $\mathrm{H}_{2}$ in the catalytic cycle. ${ }^{\sqrt{3839}}$ We hypothesize that the resulting adduct, $\mathrm{HoxH}_{2}$, is the catalytic intermediate that $\mathrm{Cl}^{-}$targets. Chloride binding leads to a species referred to as "HoxH $\mathrm{H}_{2} \mathrm{Cl}^{-}$", which can undergo a one-electron one-proton oxidation to "Hsuperox $\mathrm{H}^{-} \mathrm{Cl}^{-1}$ and then isomerisation.

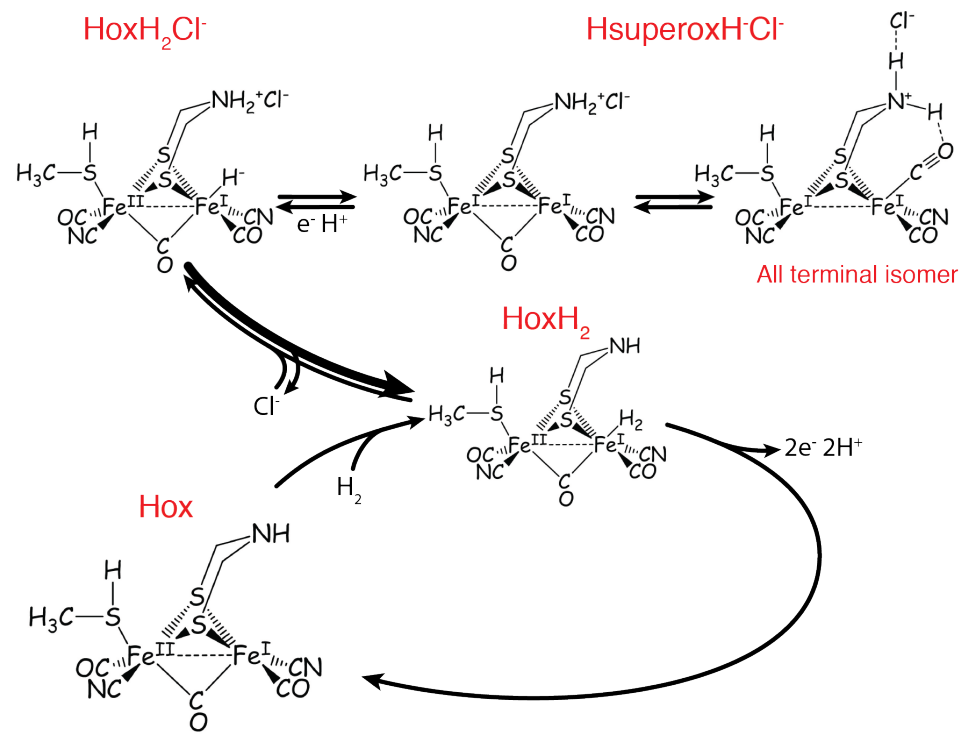

Figure 5: The mechanism of uncompetitive inhibition by chloride under oxidative conditions, according to which $\mathrm{Cl}^{-}$binds to the active site following the binding of $\mathrm{H}_{2}$. The subsequent one-proton one-electron oxidation produces two isomers of an inactive dead-end.

The above mechanism is consistent with all experimental evidence. It gives a steady-state rate equation that is typical of uncompetitive inhibition and agrees with eq. 1 and the data in fig $4 \mathrm{C}$ :

$$
v\left(E,\left[\mathrm{H}_{2}\right],\left[\mathrm{Cl}^{-}\right]\right)=\frac{v_{\max }(E)}{1+\frac{K_{m}}{\left[\mathrm{H}_{2}\right]}+\frac{\left[\mathrm{Cl}^{-}\right]}{K_{i}(E)}}
$$

The dependence of $v_{\max }$ on $E$ is described by electrokinetic models of the catalytic cycle 37140 
and the dependence of $K_{i}$ on $E$ comes from the oxidation that follows $\mathrm{Cl}^{-}$binding. The observation that the rate constant of inhibition is proportional to $\left[\mathrm{Cl}^{-}\right]$and independent of $E$ is what we expect from the scheme in fig 5 if the binding of chloride is bimolecular and if the steady-state concentration of $\mathrm{HoxH}_{2}$ is independent of potential at high potential (that is, if the rate of the catalytic step that immediately follows the formation of $\mathrm{HoxH}_{2}$ is not dependent of $E$ ). Reactivation is triggered by a one-electron one-proton reduction. The hypothesis (supported below) that two isomers of the oxidized form are in equilibrium

agrees with the experimental observation that the inactivation kinetics is biphasic, ${ }^{2627}$ from which we concluded that two inactive species are formed. This, also, is consistent with the kinetic scheme in fig 5 on condition that all steps are reversible (see SI section S3).

\section{DFT}

Here we describe DFT calculations that support the inhibition mechanism in fig 5, where $\mathrm{Cl}^{-}$targets the catalytic intermediate $\mathrm{HoxH}_{2}$; then we rule out alternatives.

We performed DFT calculations with the large model of the active site shown in figure S9 and previously described in ref 16. It includes the 28 atoms of the dinuclear cluster and of 5 amino acids that directly interact with the intrinsic ligands of the dinuclear cluster. The $\mathrm{Fe}_{4} \mathrm{~S}_{4}$ subcluster is only represented by a hydrogen atom: we ignore the possibility that redox changes at the cubane may define the reactivity that we study here. This assumption is reasonable since the cubane should remain oxidized under the very oxidizing conditions where the inhibition occurs (see SI DFT section 8 for details).

We estimated the $\mathrm{Cl}^{-}$binding energies from DFT calculations by calculating the change in energy when a chloride that is initially bound to the side chain of an arginine residue forms an adduct with the H-cluster:

$$
\mathrm{H}-\text { cluster }+\mathrm{Arg} \cdot \mathrm{Cl}^{-} \rightarrow \mathrm{H}-\text { cluster } \cdot \mathrm{Cl}^{-}+\mathrm{Arg}
$$


Arginine is not a typical biological binding site for halides, ${ }^{41}$ we only use it here to obtain an energy reference. The four systems (arginine and dinuclear cluster and their Cl- adducts) were calculated independently (SI DFT section 5).

The binding energies depend on which reference is chosen and vary by a few $\mathrm{kcal} / \mathrm{mol}$ depending on the functional adopted; however in this work, we focus only on the order of magnitude of values calculated with respect to a reference; absolute values do not matter. When we examined which forms of the H-cluster may bind $\mathrm{Cl}^{-}$, we found three different groups of species, depending on whether the binding energy is very low $(>20 \mathrm{kcal} / \mathrm{mol}$ ) or very high $(<-20 \mathrm{kcal} / \mathrm{mol})$ or small $(-2$ to $2 \mathrm{kcal} / \mathrm{mol})$. Whether a particular species belongs to one group or another is independent of the reference state or the functional used in the calculation (see SI DFT section 6). We considered that a species that has very low affinity for $\mathrm{Cl}^{-}$is probably not involved in the reactions described here. A very strong affinity is not what we are looking for either, considering that the inhibition by $\mathrm{Cl}^{-}$is fully reversible. We therefore assumed that only the species that belong to the the third group (with small $\mathrm{Cl}^{-}$binding energies) are relevant in this investigation. Indeed, at low electrode potential, we measured a dissociation constant for $\mathrm{Cl}^{-}$larger than $4 \mathrm{M}$, meaning that in the presence of $0.1 \mathrm{M} \mathrm{NaCl}$, the formation of the adduct with $\mathrm{Cl}^{-}$is unfavored by $>2 \mathrm{kcal} / \mathrm{mol}$.

We screened the effect of $\mathrm{Cl}^{-}$binding to all possible forms of the $\mathrm{H}$-cluster, starting with the species which supposedly is the target of $\mathrm{Cl}^{-}$in fig 5 . The calculated structures of the relevant species are all shown in SI section S7.

$\mathbf{H o x H}_{2}$. According to DFT, $\mathrm{Cl}^{-}$binding to the adt ligand of the adduct between Hox and $\mathrm{H}_{2}$ is slightly exothermic (binding energy $=-1.0 \mathrm{kcal} / \mathrm{mol}$ ) and the presence of $\mathrm{Cl}^{-}$favors the splitting of the H-H bond (see SI figure S11). DFT optimization of $\mathrm{HoxH}_{2} \mathrm{Cl}^{-}$results in the formation of a hydride on $\mathrm{Fe}_{d}$ and the stabilization of $\mathrm{Cl}^{-}$by a strong electrostatic interaction with the protonated $\mathrm{NH}_{2}{ }^{+}$of adt. We consider the theoretical result that $\mathrm{Cl}^{-}$ binding to this species is weak consistent with the large experimental value of $K_{i}$.

According to our hypothesis, the weak adduct between $\mathrm{HoxH}_{2}$ and $\mathrm{Cl}^{-}$is stabilized 
at high potential upon one-electron one-proton oxidation, giving a $\mathrm{Fe}(\mathrm{II}) \mathrm{Fe}(\mathrm{II})$ form with chloride and hydride bound to $\mathrm{NH}$ and $\mathrm{Fe}_{d}$, respectively, which corresponds to a local energy minimum. The $\mathrm{Fe}(\mathrm{I}) \mathrm{Fe}(\mathrm{I})$ structure in which the halide interacts with the protonated amine group is $9.6 \mathrm{kcal} / \mathrm{mol}$ more stable than the previous structure. Then, further geometry optimization (see SI DFT section 7) gives a form that is $3.5 \mathrm{kcal} / \mathrm{mol}$ more stable, where the ligands are all terminal: the rotation of the $\mathrm{Fe}_{d}(\mathrm{CO})_{2} \mathrm{CN}^{-}$group involves the movement of one equatorial $\mathrm{CO}$ to apical position and the loss of the bridging character of the $\mu \mathrm{CO}$. Two factors contribute to the stabilization of the all-terminal isomer: both Fe ions have 18 valence electrons (compared to 19 and 17 in the initial form); and the isomerization adds a weak interaction between the oxygen of the apical $\mathrm{CO}$ and the hydrogen of the protonated $\mathrm{NH}_{2}{ }^{+}$(the $\mathrm{O} / \mathrm{H}$ distance is $2.921 \AA$ ). The isomerization is barrierless at the level of theory that we use but the obstruction by nearby amino acids should add a barrier. Previous MD calculations suggested that the environment of the H-cluster is very flexible ${ }^{\sqrt{27}}$ and the rotation of the ligands around the distal Fe has been experimentally demonstrated. $\frac{5311}{5}$

We hypothesise that the two isomers of Hsuperox $\mathrm{H}^{-} \mathrm{Cl}^{-}$shown in fig 5 are the two inactive species formed at high potential. The $3.5 \mathrm{kcal} / \mathrm{mol}$ energy difference between them is consistent with the experimental observation that one inactive state is ten times more stable than the other (based on the comparison of $k_{i}^{\prime} / k_{a}{ }^{\prime}$ and $k_{i}{ }^{\prime \prime} / k_{a}{ }^{\prime \prime}$, we expect a 2.5 $\mathrm{kcal} / \mathrm{mol}$ difference). The all terminal species belongs to the group of species that weakly bind $\mathrm{Cl}^{-}$(the binding energy is $1.2 \mathrm{kcal} / \mathrm{mol}$, or $-1.1 \mathrm{kcal} / \mathrm{mol}$ after introduction of the dispersion correction within the D3 approach, see SI for details) but we consider as likely that the inactive species is kinetically stabilized: the dissociation of $\mathrm{Cl}^{-}$from the most stable isomer gives a species that is not a catalytic intermediate, so the unbinding of $\mathrm{Cl}^{-}$must be followed by a rearrangement before the activity is recovered. This process may correspond to the slow reactivation still detected in the limit of high electrode potentials (fig S7 and fig $3 \mathrm{AB}$ in ref [27).

$\mathrm{Cl}^{-}$binding to any other species than $\mathrm{HoxH}_{2}$ (obtained by oxidation and/or deprotona- 
tion of $\mathrm{HoxH}_{2}$ ) is not consistent with experimental observations, as shown hereafter.

$\mathrm{HoxH}^{-}$. We expect that the deprotonation of $\mathrm{HoxH}_{2}$ should be very difficult, because according to DFT the dihydrogen molecule is not split in $\mathrm{HoxH}_{2} \cdot{ }^{9.42}$ Moreover, the deprotonated form $\mathrm{HoxH}^{-}$does not bind $\mathrm{Cl}^{-}$(binding energy $+29.7 \mathrm{kcal} / \mathrm{mol}$ ).

HsuperoxH$H_{2}$. Oxidizing $\mathrm{HoxH}_{2}$ gives a species where the hydrogen molecule is split between a hydride on $\mathrm{Fe}_{d}$ and a proton on the $\mathrm{NH}$ of adt, resembling the catalytic intermediate "HhydH $\mathrm{H}^{+} .2143$ The charge transfer of 0.43 electrons from $\mathrm{H}^{-}$to Fe suggests the redox state assignment $\mathrm{Fe}(\mathrm{I}) \mathrm{Fe}(\mathrm{I}) . \mathrm{Cl}^{-}$binding to the $\mathrm{NH}_{2}^{+}$group is very strong $(-21.3 \mathrm{kcal} / \mathrm{mol})$ but does not affect much the structure of the cluster: the Fe-Fe bond distance is shortened by $0.099 \AA$ and the iron atomic charges are consistent with the dinuclear cluster being in the $\mathrm{Fe}(\mathrm{I}) \mathrm{Fe}(\mathrm{I})-\mathrm{H}^{+}$redox state. Such strong binding does not support the involvement of this species in the inhibition mechanism. The reason this binding does not occur is probably that Hsuperox $\mathrm{H}_{2}$ is a very unstable catalytic intermediate, which is not present in a significant amount under steady-state catalytic conditions. The two-electron oxidation of $\mathrm{HoxH}_{2}$ would give a species that binds $\mathrm{Cl}^{-}$even more strongly, therefore we also rule out the participation of this very oxidized hypothetical catalytic intermediate.

HsuperoxH $^{-}$. The catalytic intermediate obtained after one-electron one-proton oxidation of $\mathrm{HoxH}_{2}$ cannot be the target of the inhibiting $\mathrm{Cl}^{-}$. The reason for this is that further removal of one electron and one proton would give $\mathrm{HoxCl}^{-}$which cannot be the stable fully oxidized form we are looking for. Indeed, $\mathrm{Cl}^{-}$has no effect on the low potential part of the voltammogram where Hox accumulates.

Last, we briefly discuss $\mathrm{Cl}^{-}$binding to Hox and to the species obtained by the removal of either one electron or one proton from Hox. This is only for the sake of completeness, since these reactions would be responsible for competitive inhibition, in contradiction with experimental evidence.

Hox. DFT suggests that $\mathrm{Cl}^{-}$forms a stable adduct with Hox by interacting with either the distal $\mathrm{Fe}$ or the amine group of the adt ligand. The binding energies are small and 
Author version of: J. Am. Chem. Soc. 1405485 (2018)

http://dx.doi.org/doi:10.1021/jacs.8b01414

positive (1.4 and $5.7 \mathrm{kcal} / \mathrm{mol}$, respectively). In the former case, the $\mathrm{Fe}-\mathrm{Cl}^{-}$distance is much longer than in $\left[\mathrm{FeCl}_{4}\right]^{2-}(2.576 \AA$ versus $2.392 \AA$ at the same level of theory), suggesting that the anion interacts very weakly with the metal. Moreover, $\mathrm{Cl}^{-}$has a very small effect on the Fe electronic structure according to $\mathrm{NBO}$ atomic and spin charges. In both cases, $\mathrm{Cl}^{-}$ forms two electrostatic interactions with the hydrogen atoms of the amine of the adt and of the thiol of Cys178.

$\mathrm{HoxH}^{+}$and Hsuperox. There is no experimental evidence of the existence of a form of Hox that is protonated on the amine group. This hypothetical state binds $\mathrm{Cl}^{-}$too strongly (binding energy $-20.6 \mathrm{kcal} / \mathrm{mol}$ ) to be considered here. The same is true for the oxidized (all ferrous) form of Hox (binding energy $-39.6 \mathrm{kcal} / \mathrm{mol}$ ), which we know is unstable. .25127

\section{Discussion}

The buffers used to purify FeFe hydrogenases ${ }^{\sqrt{4445}}$ and those used in electrochemical experiments or spectroelectrochemical titrations ${ }^{25}$ often contain chloride. But halides are usually not ligands of inorganic active sites (except sometimes copper ions) and the observation here that chloride and bromide interact with the $\mathrm{H}$-cluster of $\mathrm{FeFe}$ hydrogenase is unprecedented and unexpected.

There are a few reports on the inhibition of metalloenzymes by halides, although with kinetic patterns that are different from the one reported here and the mechanisms are not always clear. Multicopper oxidases such as laccases ${ }^{46}$ and bilirubin oxidases ${ }^{47}$ are inhibited by $\mathrm{F}^{-}$and $\mathrm{Cl}^{-}$, which apparently interact with the T2/T3 and $\mathrm{T} 1$ sites, respectively. ${ }^{[6 / 48 / 49}$ This would explain that chloride competes with the electron donor. ${ }^{50}$ Chloride also competitively inhibits the mononuclear Mo enzyme sulfite oxidase. ${ }^{51152}$ Based on EPR investigations, it was proposed that $\mathrm{Cl}^{-}$either binds directly to the $\mathrm{Mo}^{\sqrt{53}}$ or is hydrogen-bonded to the proton of an equatorial $\mathrm{OH}$ ligand. $\frac{54}{5}$

Regarding the oxidative inactivation of FeFe hydrogenase, we consider very unlikely an 
inhibition mechanism whereby chloride would bind on a site that is remote from the $\mathrm{H}$ cluster, by accelerating or favoring whichever transformation of the H-cluster is the cause of inactivation. That the rate of inactivation tends to zero when $\left[\mathrm{Cl}^{-}\right]$tends to zero (fig 3 ) implies that chloride is absolutely required for the inactivation to proceed. The observation that replacing $\mathrm{Cl}^{-}$with $\mathrm{Br}^{-}$significantly affects the reactivation rate constants (fig 2) also suggests that the anion is bound very close to the H-cluster, in the inactive state that is formed under oxidative conditions. (We observed that chloride is the most potent anionic inhibitor of FeFe hydrogenase. Bromide is less effective than chloride, maybe because it is too large to access the H-cluster. The even larger $\mathrm{I}^{-}$has no detectable effect, nor do the very hydrated fluoride anion, sulfate and nitrate.) Our observations call for a complete revision of the previously proposed inactivation mechanisms.

There are various reasons to think that $\mathrm{Cl}^{-}$does not inhibit the enzyme by binding to Hox (or an oxidized or protonated or deprotonated form of Hox). (1) The uncompetitive nature of the inhibition - clearly demonstrated by the linear variation of the inhibition rate with $\left[\mathrm{H}_{2}\right]$ (fig 3D of ref 27 ) and by the change in apparent $K_{m}$ with $\left[\mathrm{Cl}^{-}\right]$(fig $4 \mathrm{C}$ ) implies that the halide binds to a catalytic intermediate but not to Hox, the "resting" form of the H-cluster that is present under oxidizing conditions in the absence of $\mathrm{H}_{2}$. (2) That the oxidative inactivation is a one-electron one-proton reaction (whereas no proton could be removed from a hypothetical $\mathrm{HoxCl}^{-}$adduct) also conflicts with the hypothesis that $\mathrm{Cl}^{-}$ targets Hox. According to DFT, $\mathrm{Cl}^{-}$would bind very strongly to $\mathrm{HoxH}^{+}$, but we consider this reaction unlikely because there is no experimental evidence that Hox protonates. Also this hypothesis would contradict the experimental evidence that the rate of inactivation is pH-independent (fig 3E in ref 27). The theoretical affinity of $\mathrm{Cl}^{-}$for the oxidized (all ferrous) form of Hox is large, but the formation of this adduct does not occur because overoxidation destroys the H-cluster according to spectroelectrochemical titrations (fig S2 in ref 25) and direct electrochemistry experiments. ${ }^{27]}$ (In addition, chloride binding after oxidation of Hox would be an EC mechanism, in contradiction with the experimental observation that the 
inactivation rate constants are potential independent.)

We concluded from our experimental investigation that chloride inhibits the enzyme by reversibly binding to a catalytic intermediate but the binding is weak $\left(K_{d}>4 \mathrm{M}\right)$; this is the reason chloride has no detectable effect on the low-potential part of the voltammogram: inhibition is seen only at high potential, where a one-proton one-electron oxidation locks the H-cluster into a stable, unreactive form. We sorted through all possible catalytic intermediates, in search of which is the target of $\mathrm{Cl}^{-}$. We exculpated species that are unreasonable according to DFT (e.g. obtained by removing a proton for the $\mathrm{HoxH}_{2}$ adduct) or based on experimental evidence (e.g. protonated Hox). We used the criterion that we were looking for a catalytic intermediate that weakly binds $\mathrm{Cl}^{-}$(the calculated binding energy had to be small, no more than few $\mathrm{kcal} / \mathrm{mol}$ ). We also ruled out binding of $\mathrm{Cl}^{-}$to a species obtained by removing one electron and one proton from the $\mathrm{HoxH}_{2}$ adduct, simply counting that further one-proton one-electron oxidation would give $\mathrm{HoxCl}^{-}$, which cannot be a stable dead-end since $\mathrm{Cl}^{-}$has no effect on the low-potential part of the catalytic signal.

The only option that was left corresponds to the hypothesis in fig 5, according to which $\mathrm{Cl}^{-}$targets the $\mathrm{HoxH}_{2}$ adduct. One-electron one-proton oxidation of this adduct gives the species that we referred to as "Hsuperox $\mathrm{H}^{-} \mathrm{Cl}^{-1}$, which isomerizes into the "all terminal" rightmost species. The latter has twice 18 valence electrons on the Fe ions and is likely to be a stable sink, which can slowly return to a catalytic intermediate by $\mathrm{Cl}^{-}$release and reorganization, hence the slow (but non zero) rate of reactivation in the high potential limit. The isomerization explains that the inactivation kinetics is biphasic (SI section S3). The question of which pathway(s) chloride ions use to reach the active site remains open.

According to our mechanistic hypothesis, inhibition of $\mathrm{FeFe}$ hydrogenase by $\mathrm{Cl}^{-}$does not involve the coordination of $\mathrm{Cl}^{-}$on $\mathrm{Fe}_{d}$. Indeed, in almost all the structures that we calculated, $\mathrm{Cl}^{-}$is stabilized near the amine group of adt by electrostatic interactions with the hydrogen atoms of the amine group and of the thiol of Cys178. Protonation of the amine group increases the stability of the adduct. Direct binding on $\mathrm{Fe}_{d}$ was seen only in highly 
oxidized (all-ferrous) forms of the $\mathrm{H}$-cluster, which we think are not relevant. We would have considered direct binding of $\mathrm{Cl}^{-}$onto $\mathrm{Fe}_{d}$ very surprising considering the available structural data. None of the available structures of holo FeFe hydrogenases shows a chloride near the $\mathrm{H}$-cluster (even though some crystals were obtained in the presence of $\mathrm{MgCl}_{2}$ ). We identified a putative chloride binding site $10 \AA$ from the H-cluster (see SI section S1; it is too far from the H-cluster to be relevant to our study). There are more than 3000 deposited structures that contain at least one chloride or bromide ion and at least one transition metal, only 60 of which where the anion is less than $3 \AA$ from a Fe. Among these, none is a hydrogenase and only 2 are FeS proteins (namely the ThiC and NadA radical SAM enzymes, $\frac{55156}{\sqrt{5}}$ see SI section S2).

We estimate that it may be possible in the future to produce the chloride-bound, inactive states of FeFe hydrogenase in solution experiments, to probe further the position of the $\mathrm{Cl}^{-}$ ligand. The protocol would necessarily involve the reaction of the enzyme with a strong oxydant under $\mathrm{H}_{2}$. If the experiment is carried out in the absence of mediators the reactivation reaction should be slow and the oxidized species may accumulate.

\section{Methods}

Biochemistry Samples of C. reinhardtii FeFe hydrogenase were prepared as described in ref 45.

Electrochemistry All electrochemical experiments were carried out in a glovebox (Jacomex) filled with $\mathrm{N}_{2}$, with the electrochemical set-up and equipment described in ref 57 , The enzyme was adsorbed onto a pyrolytic edge electrode by painting its surface (area $A \approx$ $\left.3 \mathrm{~mm}^{2}\right)$, previously polished with an aqueous alumina slurry $(1 \mu \mathrm{m})$ and sonicated, with $\approx$ $1 \mu L$ of an enzyme stock solution. Experiments were performed at $2^{\circ} \mathrm{C}$ in $\mathrm{pH} 7$ mixed buffer solutions, consisting of MES, HEPES, sodium acetate, TAPS and CHES (5 mM each), 1 mM EDTA and different concentrations of $\mathrm{NaCl}(0-0.3 \mathrm{M}), \mathrm{KBr}(0-0.5 \mathrm{M}), \mathrm{KI}(0-0.5$ 
M), $\mathrm{NaF}(0-0.3 \mathrm{M}), \mathrm{Na}_{2} \mathrm{SO}_{4}(0-0.1 \mathrm{M})$ or $\mathrm{KNO}_{3}(0-0.5 \mathrm{M})$. Experiments in the absence of halides were replicated in $0.1 \mathrm{M}$ phosphate buffer. In the experiments carried out in the absence of halides, the reference compartment of the cell was filled with a $0.1 \mathrm{M}$ sulfate or phosphate solution (instead of $0.1 \mathrm{M} \mathrm{NaCl}$ ) in order to prevent any contamination of the main compartment by chloride. The cell was continuously flushed with either pure $\mathrm{H}_{2}$, or, in the experiments where $\mathrm{H}_{2}$ concentration was varied, with a mixture of $\mathrm{H}_{2}$ and $\mathrm{N}_{2}$ adjusted to the desired composition using mass flow controllers (SLA5850S from BROOKS Instruments). The data were analysed using QSoas, $\frac{58}{5}$ an open source program available at http://www.qsoas.org.

Calculations The DFT computation were performed using the hybrid Generalized Gradient Approximation (GGA) BP86 $\frac{5960}{6}$ and PBE0 ${ }^{61}$ DFT functional as implemented in the TURBOMOLE suite of programs. ${ }^{62}$ Resolution-of-identity (RI) technique has been adopted to speed up computations for pure BP86 functional. Basis sets of triple- $\zeta$ plus polarization split valence quality ${ }^{63}$ were adopted for all atoms. These two level of theory are able to reproduce geometries of $\mathrm{H}$-cluster models in good agreement with experimental structures. ${ }_{64}^{64}$

Solvent effect was accounted by using the Conductor-like Screening Model (COSMO) approach. $\frac{6566}{60}$ Poket environment solvation has been considered by setting the dielectric constant within COSMO approach equal to 4. Empirical D3 dispersion correction proposed by Grimme $e^{67}$ for DFT was been also adopted at BP86 level for sake of comparison (details in SI). According to the comparison of the computed $\mathrm{Cl}^{-}$binding energies presented in table $\mathrm{S} 1, \mathrm{PBE} 0$ values are on average systematically higher about $1.5 \mathrm{kcal} / \mathrm{mol}$ compared to those computed at BP86 level. For this reason only BP86 values are presented here.

\section{Associated content}

Supporting Information The Supporting Information is available free of charge via the Internet at http://pubs .acs.org. DFT computational details and models; electronic struc- 
tures of the models; statistical analysis of the pdb; experimental PFV data for C. acetobutylicum FeFe hydrogenase (fig S2) and D. fructosovorans NiFe hydrogenase (fig S3), effect of $\mathrm{NaF}, \mathrm{KI}, \mathrm{Na}_{2} \mathrm{SO}_{4}, \mathrm{KNO}_{3}$ on C. reinhardtii $\mathrm{FeFe}$ hydrogenase (fig S4), effect of $\mathrm{Cl}^{-}$on the inhibition by $\mathrm{O}_{2}$ and $\mathrm{CO}$ (fig S5), examples of potential steps experiments with $C$. reinhardtii FeFe hydrogenase (fig $\mathrm{S} 6$ and $\mathrm{S} 7$ ), measurement of the $\mathrm{K}_{m}$ for $\mathrm{H}_{2}$ in the absence of salt (fig S8).

\section{Acknowledgement}

Our work is supported by CNRS, Aix Marseille Université, Agence Nationale de la Recherche (ANR-12-BS08-0014, ANR-14-CE05-0010, ANR-11-IDEX-0001-02) and has received funding from Excellence Initiative of Aix-Marseille University - A*MIDEX, a French "Investissements d'Avenir" programme. The French authors are part of the French bioinorganic chemistry network (www.frenchbic.cnrs.fr).

\section{References}

(1) Lubitz, W.; Ogata, H.; Rüdiger, O.; Reijerse, E. Chem. Rev. 2014, 114, 4081-4148.

(2) Winkler, M.; Senger, M.; Duan, J.; Esselborn, J.; Wittkamp, F.; Hofmann, E.; Apfel, U.-P. P.; Stripp, S. T. T.; Happe, T. Nat. commun. 2017, 8, 16115.

(3) Rumpel, S.; Sommer, C.; Reijerse, E.; Farès, C.; Lubitz, W. J. Am. Chem. Soc. 2018, 140, 3863-3866.

(4) Berggren, G.; Adamska, A.; Lambertz, C.; Simmons, T. R.; Esselborn, J.; Atta, M.; Gambarelli, S.; Mouesca, J. M.; Reijerse, E.; Lubitz, W.; Happe, T.; Artero, V.; Fontecave, M. Nature 2013, 499, 66-69.

(5) Roseboom, W.; De Lacey, A. L.; Fernandez, V. M.; Hatchikian, E. C.; Albracht, S. P. J. Biol. Inorg. Chem. 2006, 11, 102-118. 
(6) Chen, Z.; Lemon, B. J.; Huang, S.; Swartz, D. J.; Peters, J. W.; Bagley, K. A. Biochemistry 2002, 41, 2036-2043.

(7) Mulder, D. W.; Ratzloff, M. W.; Shepard, E. M.; Byer, A. S.; Noone, S. M.; Peters, J. W.; Broderick, J. B.; King, P. W. J. Am. Chem. Soc. 2013, 135, 6921-6929.

(8) Myers, W. K.; Stich, T. A.; Suess, D. L.; Kuchenreuther, J. M.; Swartz, J. R.; Britt, R. D. J. Am. Chem. Soc. 2014, 136, 12237-12240.

(9) Bruschi, M.; Greco, C.; Fantucci, P.; De Gioia, L. Inorg. Chem. 2008, 47, 6056-6071.

(10) Fiedler, A. T.; Brunold, T. C. Inorg. Chem. 2005, 44, 9322-9334.

(11) Silakov, A.; Reijerse, E. J.; Albracht, S. P. J.; Hatchikian, E. C.; Lubitz, W. J. Am. Chem. Soc. 2007, 129, 11447-11458.

(12) Adamska, A.; Silakov, A.; Lambertz, C.; Rüdiger, O.; Happe, T.; Reijerse, E.; Lubitz, W. Angew. Chem. Int. Ed. 2012, 51, 11458-11462.

(13) del Barrio, M.; Sensi, M.; Orain, C.; Baffert, C.; Dementin, S.; Fourmond, V.; Léger, C. Acc. Chem. Res. 2018, 51, 769-777.

(14) Bennett, B.; Lemon, B. J.; Peters, J. W. Biochemistry 2000, 39, 7455-7460.

(15) Liebgott, P.-P.; Leroux, F.; Burlat, B.; Dementin, S.; Baffert, C.; Lautier, T.; Fourmond, V.; Ceccaldi, P.; Cavazza, C.; Meynial-Salles, I.; Soucaille, P.; Fontecilla-Camps, J. C.; Guigliarelli, B.; Bertrand, P.; Rousset, M.; Léger, C. Nat. Chem. Biol. 2009, 6, 63-70.

(16) Baffert, C.; Bertini, L.; Lautier, T.; Greco, C.; Sybirna, K.; Ezanno, P.; Etienne, E.; Soucaille, P.; Bertrand, P.; Bottin, H.; Meynial-Salles, I.; De Gioia, L.; Léger, C. J. Am. Chem. Soc. 2011, 133, 2096-2099.

(17) Swanson, K. D.; Ratzloff, M. W.; Mulder, D. W.; Artz, J. H.; Ghose, S.; Hoffman, A.; White, S.; Zadvornyy, O. A.; Broderick, J. B.; Bothner, B.; King, P. W.; Peters, J. W. J. Am. Chem. Soc. 2015, 137, 1809-1816. 
(18) Kubas, A.; Orain, C.; De Sancho, D.; Saujet, L.; Sensi, M.; Gauquelin, C.; Meynial-Salles, I.; Soucaille, P.; Bottin, H. A.; Baffert, C.; Fourmond, V.; Best, R. B.; Blumberger, J.; Léger, C. Nat. Chem. 2017, 9, 88-95.

(19) Rodríguez-Maciá, P.; Birrell, J. A.; Lubitz, W.; Rüdiger, O. ChemPlusChem 2017, 82, 540545.

(20) Mebs, S.; Kositzki, R.; Duan, J.; Kertess, L.; Senger, M.; Wittkamp, F.; Apfel, U.-P. P.; Happe, T.; Stripp, S. T.; Winkler, M.; Haumann, M. Biochim. biophys. acta 2018, 1859, $28-41$.

(21) Fourmond, V.; Baffert, C.; Sybirna, K.; Dementin, S.; Abou-Hamdan, A.; Meynial-Salles, I.; Soucaille, P.; Bottin, H.; Leger, C. Chem. Commun. 2013, 49, 6840-6842.

(22) Sensi, M.; Baffert, C.; Fradale, L.; Gauquelin, C.; Soucaille, P.; Meynial-Salles, I.; Bottin, H.; de Gioia, L.; Bruschi, M.; Fourmond, V.; Léger, C.; Bertini, L. ACS Catal. 2017, 7, 7378-7387.

(23) Hajj, V.; Baffert, C.; Sybirna, K.; Meynial-Salles, I.; Soucaille, P.; Bottin, H.; Fourmond, V.; Leger, C. Energy Environ. Sci. 2014, 7, 715-719.

(24) Megarity, C. F.; Esselborn, J.; Hexter, S. V.; Wittkamp, F.; Apfel, U.-P.; Happe, T.; Armstrong, F. A. J. Am. Chem. Soc. 2016, 138, 15227-15233.

(25) Silakov, A.; Kamp, C.; Reijerse, E.; Happe, T.; Lubitz, W. Biochemistry 2009, 48, 7780-7786.

(26) Parkin, A.; Cavazza, C.; Fontecilla-Camps, J. C.; Armstrong, F. A. J. Am. Chem. Soc. 2006, 128, 16808-16815.

(27) Fourmond, V.; Greco, C.; Sybirna, K.; Baffert, C.; Wang, P.-H.; Ezanno, P.; Montefiori, M.; Bruschi, M.; Meynial-Salles, I.; Soucaille, P.; Blumberger, J.; Bottin, H.; De Gioia, L.; Léger, C. Nat. Chem. 2014, 6, 336-342.

(28) Sensi, M.; del Barrio, M.; Baffert, C.; Fourmond, V.; Léger, C. Curr. Op. Electrochem. 2017, $5,135-145$. 
(29) Olsen, M. T.; Rauchfuss, T. B.; Wilson, S. R. J. Am. Chem. Soc. 2010, 132, 17733-17740.

(30) Miyake, T.; Bruschi, M.; Cosentino, U.; Baffert, C.; Fourmond, V.; Léger, C.; Moro, G.; De Gioia, L.; Greco, C. J. Biol. Inorg. Chem. 2013, 18, 693-700.

(31) Senger, M.; Mebs, S.; Duan, J.; Wittkamp, F.; Apfel, U.-P. P.; Heberle, J.; Haumann, M.; Stripp, S. T. T. Proc. Natl. Acad. Sc. USA 2016, 113, 8454-8459.

(32) Greco, C.; Bruschi, M.; Heimdal, J.; Fantucci, P.; De Gioia, L.; Ryde, U. Inorg. Chem. 2007, $46,7256-7258$.

(33) Greco, C.; Bruschi, M.; Fantucci, P.; Ryde, U.; De Gioia, L. Chem. Eur. J. 2011, 17, 19541965.

(34) Cornish-Bowden, A.; Wiley, J. Fundamentals of enzyme kinetics; Wiley-Blackwell, Weinheim, 2014.

(35) Fourmond, V.; Lautier, T.; Baffert, C.; Leroux, F.; Liebgott, P.-P.; Dementin, S.; Rousset, M.; Arnoux, P.; Pignol, D.; Meynial-Salles, I.; Soucaille, P.; Bertrand, P.; Léger, C. Anal. Chem. 2009, 81, 2962-2968.

(36) Hamdan, A. A.; Liebgott, P.-P.; Fourmond, V.; Gutiérrez-Sanz, O.; De Lacey, A. L.; Infossi, P.; Rousset, M.; Dementin, S.; Léger, C. Proc. Natl. Acad. Sc. USA 2012, 109, 19916-19921.

(37) Fourmond, V.; Léger, C. Curr. Op. Electrochem. 2017, 1, 110-120.

(38) Fan, H. J.; Hall, M. B. J. Am. Chem. Soc. 2001, 123, 3828-3829.

(39) Zampella, G.; Greco, C.; Fantucci, P.; De Gioia, L. Inorg. Chem. 2006, 45, 4109-4118.

(40) Fourmond, V.; Baffert, C.; Sybirna, K.; Lautier, T.; Abou Hamdan, A.; Dementin, S.; Soucaille, P.; Meynial-Salles, I.; Bottin, H.; Léger, C. J. Am. Chem. Soc. 2013, 135, 3926-3938.

(41) Blasiak, L. C.; Drennan, C. L. Acc. Chem. Res. 2009, 42, 147-155.

(42) Mulder, D. W.; Ratzloff, M. W.; Bruschi, M.; Greco, C.; Koonce, E.; Peters, J. W.; King, P. W. J. Am. Chem. Soc 2014, 136, 15394-15402. 
(43) Reijerse, E. J.; Pham, C. C.; Pelmenschikov, V.; Gilbert-Wilson, R.; Adamska-Venkatesh, A.; Siebel, J. F.; Gee, L. B.; Yoda, Y.; Tamasaku, K.; Lubitz, W.; Rauchfuss, T. B.; Cramer, S. P. J. Am. Chem. Soc. 2017, 139, 4306-4309.

(44) Kamp, C.; Silakov, A.; Winkler, M.; Reijerse, E. J.; Lubitz, W.; Happe, T. Biochim. biophys. acta 2008, 17r7, 410-416.

(45) Sybirna, K.; Antoine, T.; Lindberg, P.; Fourmond, V.; Rousset, M.; Méjean, V.; Bottin, H. BMC biotechnology 2008, 8, 73+.

(46) Di Bari, C.; Mano, N.; Shleev, S.; Pita, M.; Lacey, D. J. Biol. Inorg. Chem. 2017, 22, 11791186.

(47) de Poulpiquet, A.; Kjaergaard, C. H.; Rouhana, J.; Mazurenko, I.; Infossi, P.; Gounel, S.; Gadiou, R.; Giudici-Orticoni, M. T.; Solomon, E. I.; Mano, N.; Lojou, E. ACS Catal. 2017, 7, 3916-3923.

(48) See however the structure in ref 49 where a putative chloride is bound to the T2 copper.

(49) Hakulinen, N.; Andberg, M.; Kallio, J.; Koivula, A.; Kruus, K.; Rouvinen, J. J. Struct. Biol. 2008, 162, 29-39.

(50) Naki, A.; Varfolomeev, S. D. Biochemistry (Moscow) 1981, 46, 1344-1350.

(51) Rajapakshe, A.; Johnson-Winters, K.; Nordstrom, A. R.; Meyers, K. T.; Emesh, S.; Astashkin, A. V.; Enemark, J. H. Biochemistry 2010, 49, 5154-5159.

(52) Bray, R. C.; Gutteridge, S.; Lamy, M. T.; Wilkinson, T. Biochem. J. 1983, 211, 227-236.

(53) Doonan, C. J.; Wilson, H. L.; Bennett, B.; Prince, R. C.; Rajagopalan, K. V.; George, G. N. Inorg. Chem. 2008, 47, 2033-2038.

(54) Klein, E. L.; Astashkin, A. V.; Ganyushin, D.; Riplinger, C.; Johnson-Winters, K.; Neese, F.; Enemark, J. H. Inorg. Chem. 2009, 48, 4743-4752. 
(55) Fenwick, M. K.; Mehta, A. P.; Zhang, Y.; Abdelwahed, S. H.; Begley, T. P.; Ealick, S. E. Nat. commun. 2015, 6, 6480 .

(56) Fenwick, M. K.; Ealick, S. E. Biochemistry 2016, 55, 4135-4139.

(57) Léger, C.; Dementin, S.; Bertrand, P.; Rousset, M.; Guigliarelli, B. J. Am. Chem. Soc. 2004, 126, 12162-12172.

(58) Fourmond, V. Anal. Chem. 2016, 88, 5050-5052.

(59) Perdew, J. P. Phys. rev. B 1986, 33, 8822-8824.

(60) Becke, A. D. Phys. rev. A 1988, 38, 3098-3100.

(61) Adamo, C.; Scuseria, G. E.; Barone, V. J. Chem. Phys. 1999, 111, 2889-2899.

(62) Ahlrichs, R.; Bär, M.; Häser, M.; Horn, H.; Kölmel, C. Chem. Phys. Lett. 1989, 162, 165 169.

(63) Schäfer, A.; Huber, C.; Ahlrichs, R. J. Chem. Phys. 1994, 100, 5829-5835.

(64) Bertini, L.; Alberto, M. E.; Arrigoni, F.; Vertemara, J.; Fantucci, P.; Bruschi, M.; Zampella, G.; De Gioia, L. Int. J. Quantum Chem. 2017, 117, e25537.

(65) Klamt, A. J. Phys. Chem. 1995, 99, 2224-2235.

(66) Klamt, A.; Schuurmann, G. J. Chem. Soc., Perkin Trans. 2 1993, 799-805.

(67) Grimme, S.; Antony, J.; Ehrlich, S.; Krieg, H. J. Chem. Phys. 2010, 132, 154104. 
Author version of: J. Am. Chem. Soc. 1405485 (2018)

http://dx.doi.org/doi:10.1021/jacs.8b01414

\section{Supplementary Information}

Interaction of the H-cluster of FeFe hydrogenase with halides.

Melisa del Barrio, Matteo Sensi, Laura Fradale, Maurizio Bruschi, Claudio Greco, Luca de Gioia, Luca Bertini, Vincent Fourmond, Christophe Léger.

\section{S1 Chloride anions in FeFe hydrogenases and a putative chloride binding site near the protein surface}

The 4R0V structure of the $\mathrm{O}_{2}$-damaged enzyme from $\mathrm{Cr}$ shows a $\mathrm{Cl}^{-}$anion $(/ 4 \mathrm{r} 0 \mathrm{v} / / \mathrm{B} / \mathrm{CL}$ ' $602 /)$ at the position of the distal CN from the missing dinuclear cluster and another chloride (/4r0v//B/CL'603/) in a remote site, referred to as site A below, that is near the protein surface, $9.5 \AA$ from CL' 602 . The $3 \mathrm{LX} 4$ structure of the apo hydrogenase from Cr has a water molecule $\left(/ 31 \times 4 / / \mathrm{B} / \mathrm{HOH}^{\prime} 534 / 0\right)$ in site $\mathrm{A}$; the same water molecule is seen in the structures of various natural or semisynthetic $\mathrm{CpI} F \mathrm{FeFe}$-hydrogenases which have no chloride in the pdb file but have been obtained in the presence of $\mathrm{MgCl}_{2}: 44 \mathrm{xdc} / / \mathrm{B} / \mathrm{HOH}^{\text {' }} 1057$, /5byq//B/HOH'1046, /5byr//B/HOH'843, /5bys//B/HOH'801, /5la3//A/HOH'799, /5oef/ /A/HOH' 851 . The 4XDD structure of apo CpI FeFe hydrogenase, crystallized in the presence of $\mathrm{MgCl}_{2}$, has a $\mathrm{Cl}^{-}(/ 4 \mathrm{xdd} / / \mathrm{B} / \mathrm{CL}$ '606) at the position of the proximal $\mathrm{CN}$ of the missing binuclear cluster, one on the surface (/4xdd//B/CL'607) and again a water molecule in site A (/4xdd//B/HOH' 1050). We suggest that this conserved water molecule in site A may be a misassigned conserved chloride with low occupancy.

There is no chloride and no water in site $\mathrm{A}$ in the $1 \mathrm{HFE}$ structure of the enzyme D. desulfuricans and the $3 \mathrm{C} 8 \mathrm{Y}$ structure of $\mathrm{Cp}$ hydrogenase. 


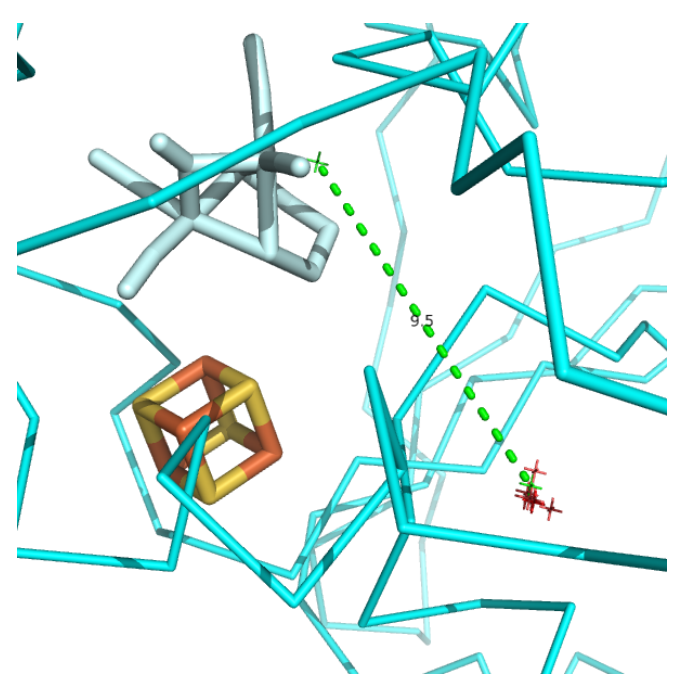

Figure S1: The cubane of the damaged $\mathrm{H}$ cluster in $\mathrm{pdb} 4 \mathrm{R} 0 \mathrm{~V}$, the location of the missing dinuclear cluster indicated in grey, the chloride anion near the cubane (/4r0v//B/CL'602/), and that in site A (CL'603), both shown as green crosses, and the conserved water molecules in site A shown as red crosses.

\section{S2 Chloride or bromide bound to iron in PDB structures}

We found 3274 structures that contain either a chloride or a bromide ion, and either Fe, $\mathrm{Cu}, \mathrm{Mn}, \mathrm{Zn}, \mathrm{Ni}$, or Mo. Out of these, the following PDB accession codes corresponded to structures in which a $\mathrm{Cl}^{-}$ion is found closer than $3 \AA$ from a Fe ion: 1A7D, 1BES, 1I4Y, 1ZJ8, 1ZJ9, 2AWY, 2FCT, 3AGT, 3AGU, 3ARJ, 3ARK, 3ARL, 3HX9, 3NNF, 3NNL, 3VEC, 3VED, 3VLX, 3WFB, 3WHN, 3WSD, 4CUD, 4JET, 4LQJ, 4LQN, 4LQV, 4LYU, 4LYX, 4MJY, 4MN9, 4MY7, 4OYN, 4PIX, 4S25, 4S26, 4S27, 4S28, 4UBH, 4XET, 4XEZ, 4XF0, 4XFB, 4XFC, 4XFF, 4XFG, 4Y08, 4YKH, 4YYO, 4ZJK, 5H8Y, 5IOR, 5IQS, 5IQT, 5IQV, 5J93, 5J9V, 5JAC, 5JKK, 5JKL, 5KTM, 5KTR, 5KTS.

Among these structures, we found only two distinct proteins in which the $\mathrm{Cl}^{-}$ion is bound to a $[4 \mathrm{Fe}-4 \mathrm{~S}]$ cluster:

- the quinolinate synthase (5KTM)

- the thiamin pyrimidine synthase $(4 \mathrm{~S} 25,4 \mathrm{~S} 26,4 \mathrm{~S} 27$ and 4S28)

These enzymes belong to the radical SAM family, and the $\mathrm{Cl}^{-}$ion binds at the vacant coordination position on the SAM cluster.

Only one corresponded to a bromide bound to an iron: 2 FCV. 


\section{S3 Biphasics inactivation kinetics}

The model given in figure 5 can be schematized thus:

$$
\mathrm{A} \underset{k_{-1}}{\stackrel{k_{1}}{\rightleftharpoons}} \mathrm{I}_{1} \underset{k_{-2}}{\stackrel{k_{2}}{\rightleftharpoons}} \mathrm{I}_{2}
$$

in which the first reaction corresponds to binding of $\mathrm{Cl}^{-}$and oxidation, and the second reaction to the isomerisation. The differential equation governing the evolution over time of the active species $a(t)$ can be put under the following form:

$$
\frac{\mathrm{d}^{2} a}{\mathrm{~d} t^{2}}+\Sigma \frac{\mathrm{d} a}{\mathrm{~d} t}+\sigma a=\sigma a^{\infty}
$$

in which:

$$
\Sigma=k_{1}+k_{-1}+k_{2}+k_{-2} \quad \sigma=k_{1} k_{2}+k_{-1} k_{-2}+k_{-1} k_{2} \quad a^{\infty}=\frac{k_{-1} k_{-2}}{\sigma}
$$

The solution can be put under the general form:

$$
a(t)=a^{\infty}+a_{+} \exp -t / \tau_{+}+a-\exp -t / \tau_{-}
$$

in which $a_{+}$and $a_{-}$are integration constants, and $1 / \tau_{ \pm}$are the roots of the polynomial $x^{2}+\Sigma x+\sigma$. The above equation corresponds to a biphasic evolution, so that scheme (S1) yields biphasic evolutions of the concentration of the active species.

This biphasicity arises from the reverse reaction $k_{-1}$, which introduces a dependence of the concentration of the active species A on the concentration of $I_{1}$, which in turns depends on $\mathrm{I}_{2}$. If $k_{-1}=0$, the evolution of the concentrations of $\mathrm{I}_{1}$ and $\mathrm{I}_{2}$ over time is biphasic but the concentration of $\mathrm{A}$ is a single exponential decay with a time constant $1 / k_{1}$. 


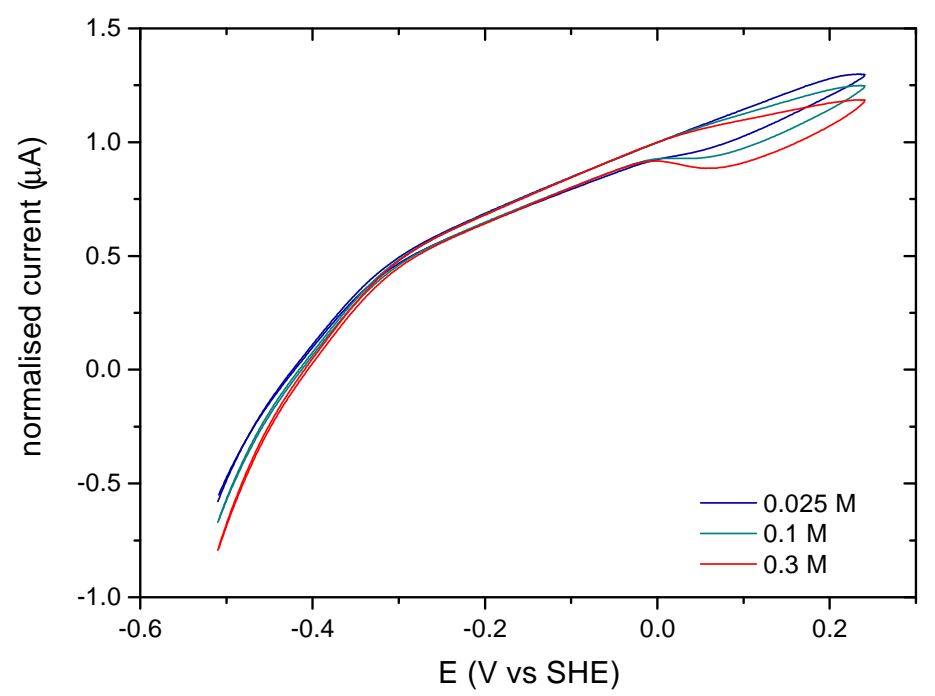

Figure S2: Effect of chloride on the voltammetric response of $C$. acetobutylicum FeFe hydro-

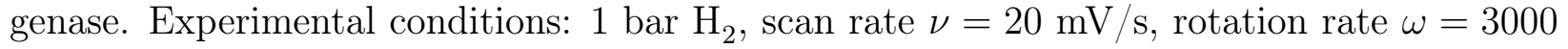
$\mathrm{rpm}, \mathrm{T}=12^{\circ} \mathrm{C}$, the concentration of chloride was varied by adding a solution of $\mathrm{NaCl}$ to a $5 \mathrm{mM}$ mixed buffer solution at $\mathrm{pH} 7$.

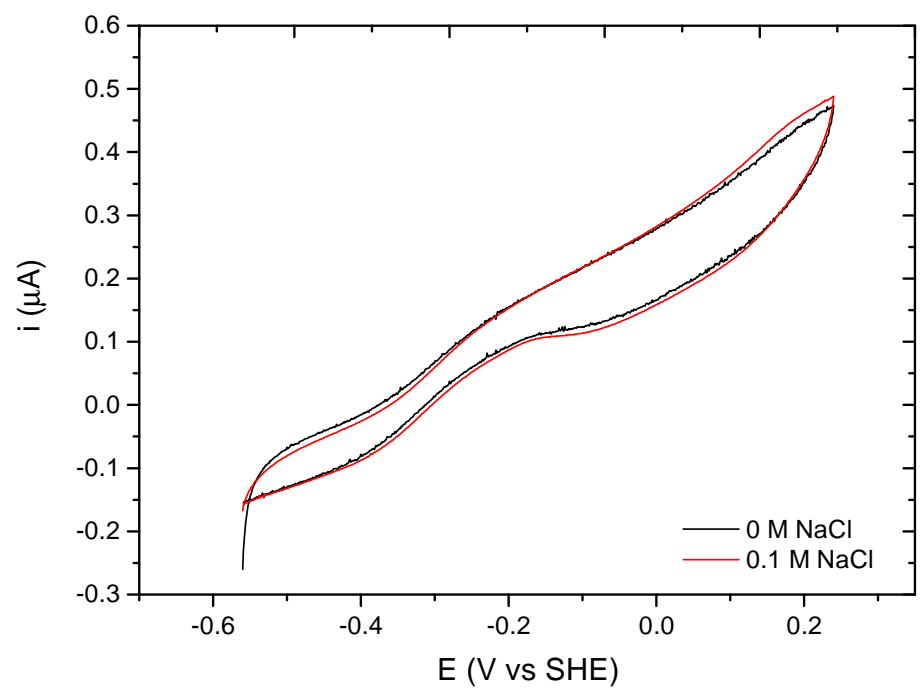

Figure S3: Cyclic voltammograms of D. fructosovorans NiFe hydrogenase showing reversible inactivation at high potential in the absence of $\mathrm{Cl}^{-}$(in black) and in the presence of $0.1 \mathrm{M}$ $\mathrm{Cl}^{-}$(in red). Experimental conditions: 0.1 bar $\mathrm{H}_{2}$, scan rate $\nu=0.5 \mathrm{mV} / \mathrm{s}$, rotation rate $\omega=3000 \mathrm{rpm}, \mathrm{T}=40^{\circ} \mathrm{C}$, in $5 \mathrm{mM}$ mixed buffer solution at $\mathrm{pH} 7$. 


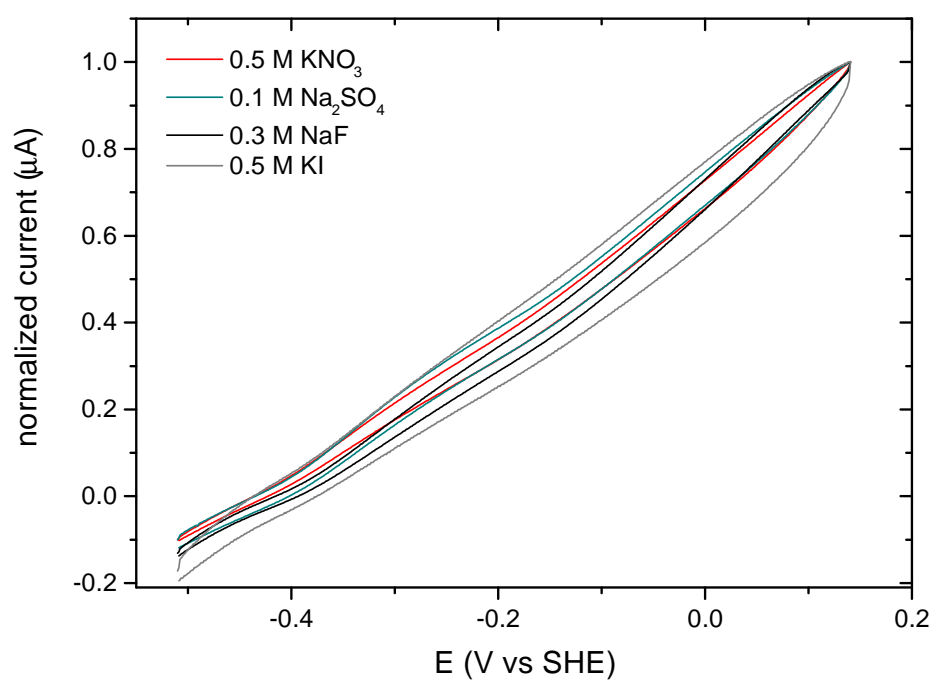

Figure S4: Cycling voltammograms of $C$. reinhardtii hydrogenase showing the absence of observable effect of $\mathrm{NaF}, \mathrm{KI}, \mathrm{KNO}_{3}$ and $\mathrm{Na}_{2} \mathrm{SO}_{4}$ on the voltammetric response. Experimental conditions: 1 bar $\mathrm{H}_{2}$, scan rate $\nu=20 \mathrm{mV} / \mathrm{s}$, rotation rate $\omega=3000 \mathrm{rpm}, T=2{ }^{\circ} \mathrm{C}$, $[\mathrm{NaF}]=0.3 \mathrm{M},\left[\mathrm{KNO}_{3}\right]=0.5 \mathrm{M},\left[\mathrm{Na}_{2} \mathrm{SO}_{4}\right]=0.1 \mathrm{M}$ and $[\mathrm{KI}]=0.5 \mathrm{M}$ (all in $5 \mathrm{mM}$ mixed buffer solution at $\mathrm{pH} 7$ ).

A

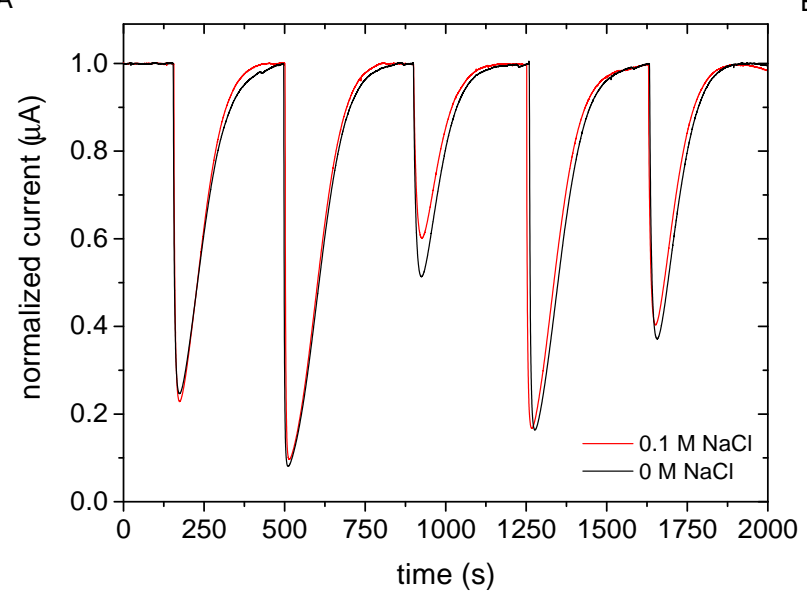

B

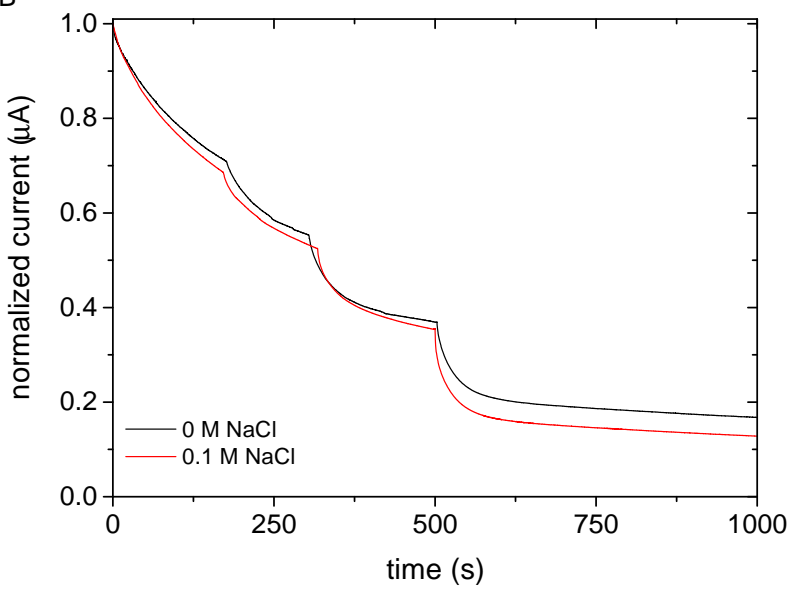

Figure S5: Absence of effect of chloride on the kinetics of inhibition by $\mathrm{CO}(\mathrm{A})$ and $\mathrm{O}_{2}(\mathrm{~B})$ of $C$. reinhardtii hydrogenase. A: $[\mathrm{CO}]=4,10,1,6,2 \mu \mathrm{M}, E=-160 \mathrm{mV}, T=30^{\circ} \mathrm{C} . \mathrm{B}:\left[\mathrm{O}_{2}\right]$ $=1,6,24 \mu \mathrm{M}, E=40 \mathrm{mV}, T=12^{\circ} \mathrm{C}$. Other experimental conditions: 1 bar $\mathrm{H}_{2}$, rotation rate $\omega=3000 \mathrm{rpm}$, pH 7 mixed buffer $0.1 \mathrm{M} \mathrm{NaCl}$ (in red) and $0 \mathrm{M} \mathrm{NaCl}$ (in black); small aliquots of buffer solution saturated with $\mathrm{CO}$ or $\mathrm{O}_{2}$ and kept in a capped septum-sealed tube were injected into the cell with a gas-tight syringe. 

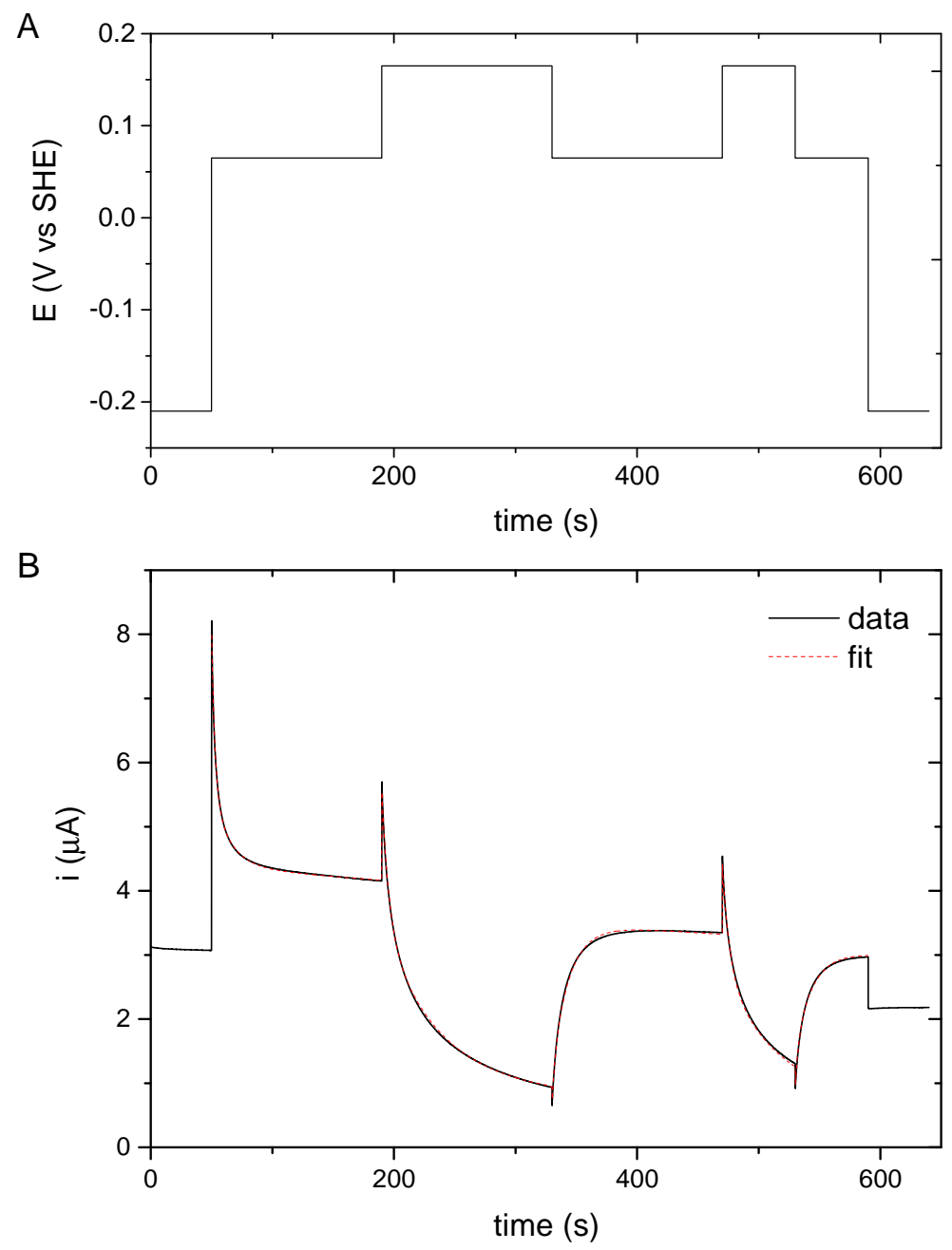

Figure S6: Chronoamperometric experiment performed with C. reinhardtii FeFe hydrogenase. A: Potential steps applied to the electrode. B: Resulting current (black) and fit to the kinetic model indicated in the main text (red). Experimental conditions: 1 bar $\mathrm{H}_{2}$, rotation rate $\omega=3000 \mathrm{rpm}, T=2^{\circ} \mathrm{C}$, in mixed buffer $\mathrm{pH} 7,0.05 \mathrm{M} \mathrm{NaCl}$. 

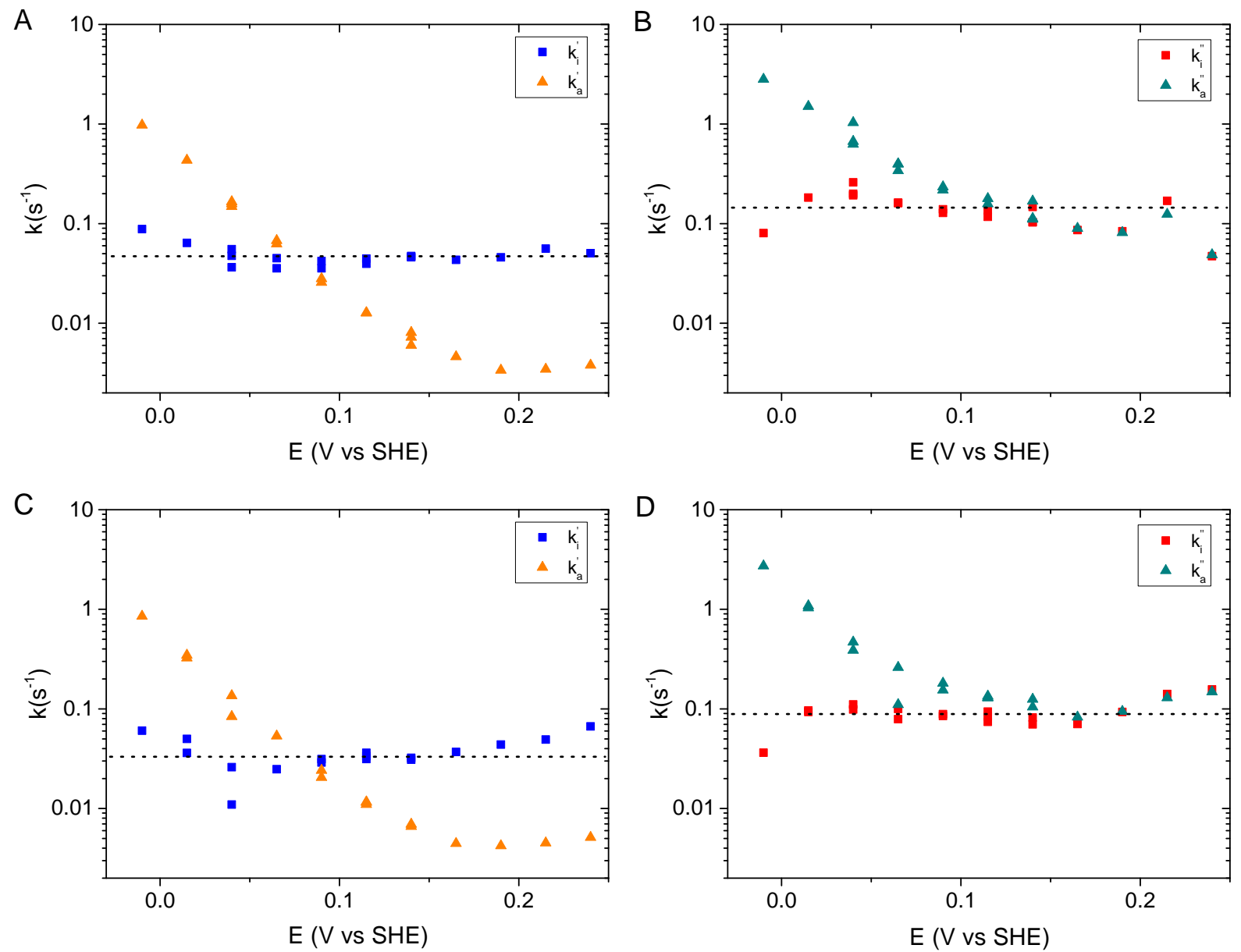

Figure S7: Dependence on potential of the inactivation $\left(k_{i}\right)$ and reactivation $\left(k_{a}\right)$ rate constants at $\left[\mathrm{Cl}^{-}\right]=0.1 \mathrm{M}$ (in panels $\mathrm{A}$ and $\mathrm{B}$ ) and $\left[\mathrm{Cl}^{-}\right]=0.05 \mathrm{M}$ (in panels $\mathrm{C}$ and $\mathrm{D}$ ). Panels $\mathrm{A}$ and $\mathrm{C}$ show the inactivation and reactivation rate constants $k_{i}^{\prime}$ and $k_{a}^{\prime}$ corresponding to the species I', and panels B and D, $k_{i}^{\prime \prime}$ and $k_{a}^{\prime \prime}$ corresponding to the species I". Conditions: 1 bar $\mathrm{H}_{2}, T=2^{\circ} \mathrm{C}$, mixed buffer $\mathrm{pH} 7$. 

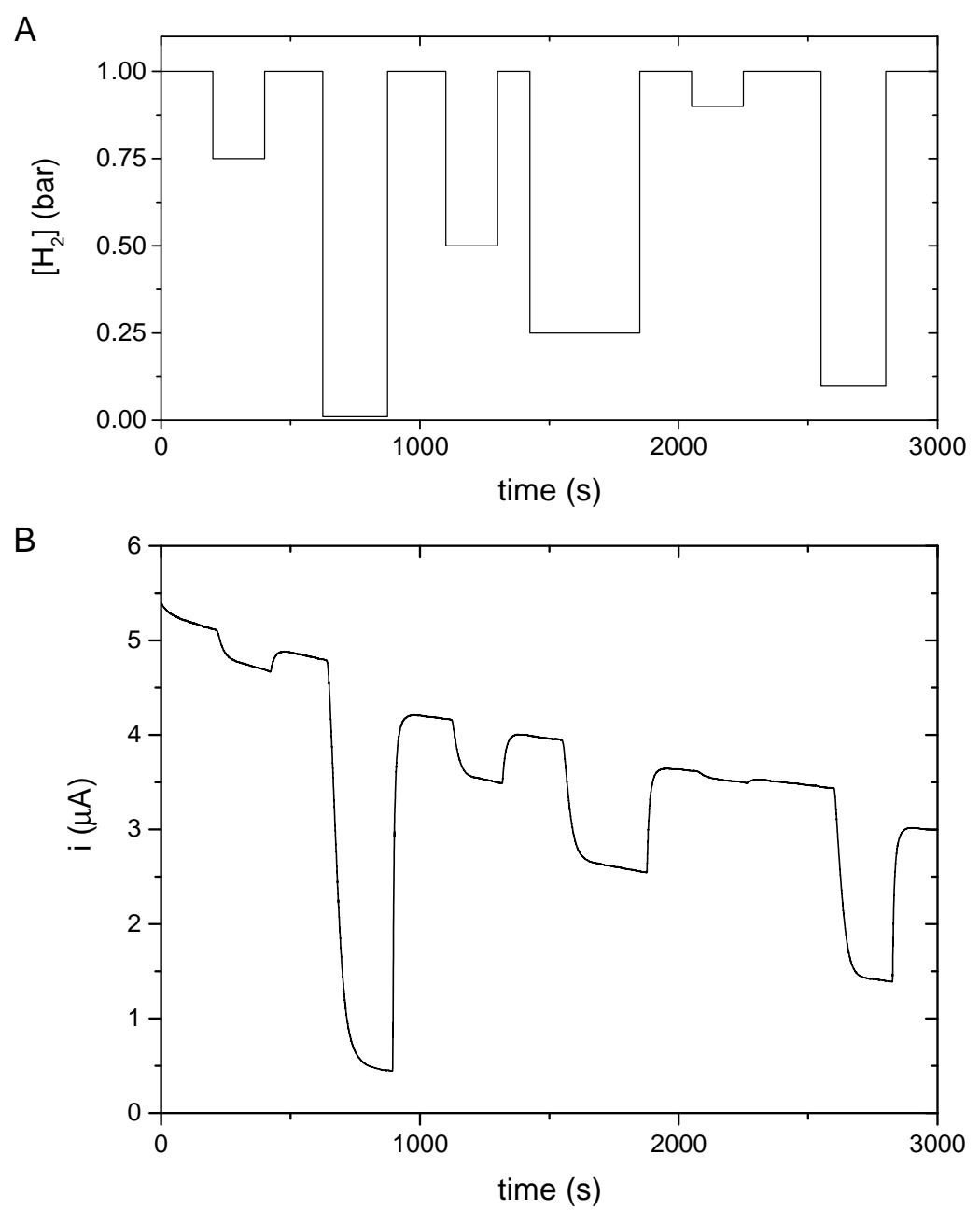

Figure S8: Chronoamperometric experiment at high potential obtained with C. reinardtii hydrogenase. A: Concentration of $\mathrm{H}_{2}$ against time. B: Resulting current at $\left[\mathrm{Cl}^{-}\right]=0 \mathrm{M}$. Experimental conditions: $E=115 \mathrm{mV}$, rotation rate $\omega=3000 \mathrm{rpm}, T=2{ }^{\circ} \mathrm{C}$, in mixed buffer pH 7. 


\section{S4. The model}

The $\mathrm{Fe}_{2} \mathrm{~S}_{2}$ large model of the $\mathrm{H}$-cluster adopted in this paper is sketched in Figure $\mathrm{S} 9$ and consists of the $\mathrm{Fe}_{2} \mathrm{~S}_{2}$ core in which the $\mathrm{Fe}_{4} \mathrm{~S}_{4}$ cubane is substituted by an hydrogen atom. Around the binuclear core, we considered the 5 residues that directly interact with the cyanide ligands (Ala107, Ile204, Lys237, Glu240) and the amine group that belongs to the ADT(Cys178). The carbon atoms in red in Figure S9 were kept fixed at the crystallographic positions $\left(1 \mathrm{FEH}^{1}\right)$ during calculations to avoid unrealistic conformational rearrangements.

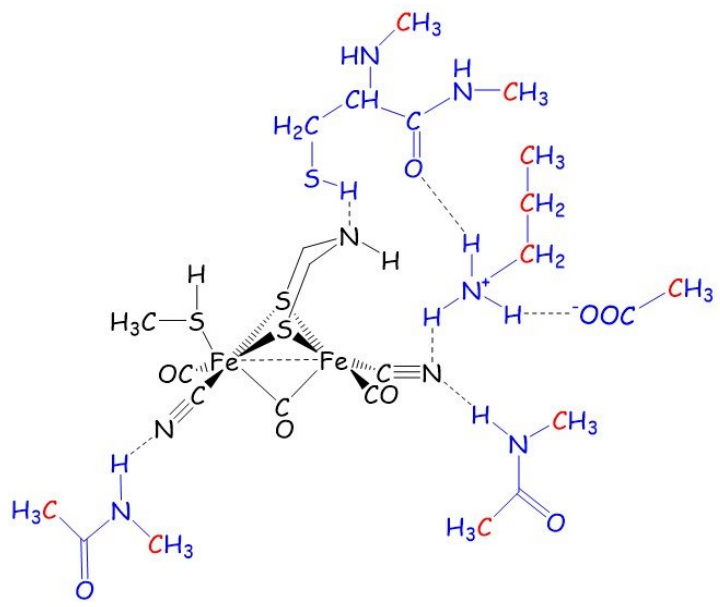

Figure S9. $\mathrm{Fe}_{2} \mathrm{~S}_{2}$ model. The carbon atoms in red were kept fixed at the crystallographic positions found in the x-ray structure of $C$. pasteurianum FeFe hydrogenase, pdb $1 \mathrm{FEH}^{1}$.

\section{S5. Details about the calculations of the binding energy}

Computational details. DFT computations were performed using the Gradient Approximation (GGA) pure BP86 and PBE0 hybrid functionals as implemented in the TURBOMOLE suite of programs. Basis sets of triple- $\zeta$ plus polarization split valence quality were adopted for all atoms. The Resolution of Identity (RI) technique was adopted for pure functionals in order to save CPU time. DFT grid-size was set to standard m3 value. Ground state geometry optimizations were carried out with convergence criteria fixed to $10^{-6}$ hartree for the energy and 0.001 hartree $\cdot$ bohr $^{-1}$ for the gradient norm vector. Atomic and spin charges are computed within Natural bond order (NBO) approach.

Computation of the chloride binding energy. The values of the $\mathrm{Cl}^{-}$binding energies have been estimated according to the following reaction:

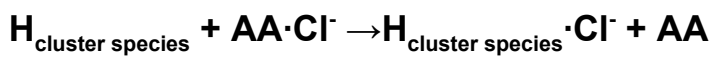


Any $\mathrm{H}$-cluster species forms a chloride adduct $\mathrm{H}_{\text {cluster species }} \cdot \mathrm{Cl}^{-}$in which the anion comes from the side chain of an arginine or threonine residue. All the systems involved were computed separately.<smiles>CCCCNC(=N)N</smiles>

$\mathbf{R}$<smiles>CCCCNC1=N[CH][CH]N1</smiles>

$\mathbf{R} \cdot \mathrm{Cl}^{-}$<smiles>CC(C)O</smiles>

$\mathbf{T}$<smiles>CC(C)OCCl</smiles>

$\mathrm{T} \cdot \mathrm{Cl}^{-}$

\section{S6. Comparison between DFT functionals}

Since the $\mathrm{Cl}^{-}$binding energies are crucial in the discussion of the inhibition mechanism, we assessed their variability as a function of the level of theory adopted, namely:

1) DFT functional adopted

2) Implicit solvation

3) Dispersion correction

4) Reference state for free $\mathrm{Cl}^{-}$

In the following we adopted the ordinary nomenclature

- $\mathrm{Fe}(\mathrm{I}) \mathrm{Fe}(\mathrm{I}) \mathrm{Hred}$

- $\mathrm{Fe}(\mathrm{I}) \mathrm{Fe}(\mathrm{II}) \mathrm{Hox}$.

- Higher oxidized forms

- Hsuperox formally $\mathrm{Fe}(\mathrm{II}) \mathrm{Fe}(\mathrm{II})$

- Hsupersuperox formally $\mathrm{Fe}(\mathrm{II}) \mathrm{Fe}(\mathrm{III})$

- $\mathrm{H}$ species $\mathrm{Cl}^{-}$is the lowest energy $\mathrm{Cl}^{-}$adduct 
Table S1. $\mathrm{Cl}^{-}$binding energies (in $\mathrm{kcal} / \mathrm{mol}$ ) computed at different levels of theory defined by the DFT functional adopted, by considering the implicit solvation (dielectric constant equal to 4) and the dispersion correction (D3) and the $\mathrm{Cl}^{-}$reference state (neutral $(R)$ or positively charged $(R+)$ arginine side chain, threonine $(T)$ ).

\begin{tabular}{|c|c|c|c|c|c|c|}
\hline & $\begin{array}{l}\text { BP86 } \\
\text { gas } \\
\text { phase R }\end{array}$ & $\begin{array}{l}\text { BP86 } \\
\varepsilon=4 R\end{array}$ & $\begin{array}{l}\text { BP86 } \\
\varepsilon=4 \mathrm{R}+\end{array}$ & $\begin{array}{l}\text { BP86 } \\
\varepsilon=4 T\end{array}$ & $\begin{array}{l}\text { BP86 } \\
\varepsilon=4 \text { D3 } \\
R\end{array}$ & $\begin{array}{l}\text { PBE0 } \\
\varepsilon=4 R\end{array}$ \\
\hline Hox $-\mathrm{Cl}^{-}$ & 10.6 & 1.4 & 45.7 & 2.7 & 0.1 & 2.3 \\
\hline $\mathrm{Hox}-\mathrm{H}_{2}-\mathrm{Cl}^{-}$ & 6.0 & -1.0 & 43.3 & 0.3 & 0.2 & -1.8 \\
\hline $\mathrm{Hox}-\mathrm{H}^{-} \mathrm{Cl}^{-}$ & 71.4 & 28.7 & 72.9 & 30.0 & 30.5 & 29.5 \\
\hline Hsuperox $-\mathrm{H}_{2}-\mathrm{Cl}^{-}$ & -50.9 & -21.2 & 23.1 & -19.9 & -24.2 & -19.8 \\
\hline Hsuperox- $\mathrm{H}^{-} \mathrm{Cl}^{-}$ & 8.6 & 1.2 & 45.5 & 2.5 & -1.1 & 5.6 \\
\hline Hsupersuperox- $\mathrm{H}^{-} \mathrm{Cl}^{-}$ & -44.8 & -20.6 & 23.7 & -19.3 & -24.5 & -18.4 \\
\hline
\end{tabular}

Table S2. Optimized Fe-Fe bond distances (in $\AA$ ) of all the species considered at BP86/TZVP/COSMO and $\mathrm{PBE}$ /TZVP/COSMO levels. Fe-Fe and $\mathrm{Fe}-\mathrm{Fe}(\mathrm{Cl})$ refer to the same iron-iron bond distance in the $\mathrm{H}$-cluster form and in its most stable $\mathrm{Cl}$ - adduct.

\begin{tabular}{|c|c|c|c|c|}
\hline & \multicolumn{2}{|c|}{ BP86 $\varepsilon=4$ R } & \multicolumn{2}{|c|}{ PBE0 $\varepsilon=4 \mathrm{R}$} \\
\hline & $\mathrm{Fe}-\mathrm{Fe}$ & $\mathrm{Fe}-\mathrm{Fe}(\mathrm{Cl})$ & $\mathrm{Fe}-\mathrm{Fe}$ & $\mathrm{Fe}-\mathrm{Fe}(\mathrm{Cl})$ \\
\hline Hox-Cl- & 2.543 & 2.636 & 2.519 & 2.635 \\
\hline $\mathrm{Hox}-\mathrm{H}_{2}-\mathrm{Cl}^{-}$ & 2.544 & 2.619 & 2.632 & 2.606 \\
\hline Hox-H-Cl${ }^{-}$ & 2.664 & 2.628 & 2.650 & 2.758 \\
\hline Hsuperox $-\mathrm{H}_{2}-\mathrm{Cl}^{-}$ & 2.515 & 2.521 & 2.544 & 2.523 \\
\hline Hsuperox- $\mathrm{H}^{-} \mathrm{Cl}^{-}$ & 2.519 & 2.584 & 2.521 & 2.506 \\
\hline Hsupersuperox $-\mathrm{H}^{-} \mathrm{Cl}^{-}$ & 2.516 & 2.636 & 2.520 & 2.638 \\
\hline
\end{tabular}


Table S3. NBO Fe proximal $\left(\mathrm{Fe}_{\mathrm{p}}\right)$ and distal $\left(\mathrm{Fe}_{\mathrm{d}}\right)$ atomic and spin charges.

\begin{tabular}{|c|c|c|c|c|c|c|c|c|c|}
\hline & & \multicolumn{4}{|c|}{ BP86 $\varepsilon=4$ R } & \multicolumn{4}{|c|}{ PBE0 $\varepsilon=4$ R } \\
\hline & & \multirow[b]{2}{*}{$q(f e)$} & \multirow[b]{2}{*}{$\mathrm{s}(\mathrm{Fe})$} & \multicolumn{2}{|c|}{ Bound $\mathrm{Cl}^{-}$} & \multirow[b]{2}{*}{$q(f e)$} & \multirow[b]{2}{*}{$\mathrm{s}(\mathrm{Fe})$} & \multicolumn{2}{|c|}{ Bound $\mathrm{Cl}^{-}$} \\
\hline & & & & $q(f e)$ & $s(\mathrm{Fe})$ & & & $q(f e)$ & $\mathrm{s}(\mathrm{Fe})$ \\
\hline \multirow{2}{*}{ Hred } & $\mathrm{Fe}_{\mathrm{p}}$ & -0.11 & 0 & & & & & & \\
\hline & $\mathrm{Fe}_{\mathrm{d}}$ & -0.16 & 0 & & & & & & \\
\hline \multirow{2}{*}{ Hox-Cl- } & $\mathrm{Fe}_{\mathrm{p}}$ & -0.13 & 0.14 & -0.10 & 0.04 & -0.05 & 0.10 & 0.12 & 0.41 \\
\hline & $\mathrm{Fe}_{\mathrm{d}}$ & 0.06 & 0.85 & 0.36 & 0.55 & 0.13 & 1.00 & -0.04 & 0.50 \\
\hline \multirow{2}{*}{ Hox $-\mathrm{H}_{2}-\mathrm{Cl}^{-}$} & $\mathrm{Fe}_{\mathrm{p}}$ & -0.07 & 0.46 & -0.05 & 0.61 & -0.03 & 0.47 & 0.05 & 0.81 \\
\hline & $\mathrm{Fe}_{\mathrm{d}}$ & -0.15 & 0.42 & -0.24 & 0.22 & -0.07 & 0.41 & -0.20 & 0.19 \\
\hline \multirow{2}{*}{$\mathrm{Hox}-\mathrm{H}^{-} \mathrm{Cl}^{-}$} & $\mathrm{Fe}_{\mathrm{p}}$ & -0.06 & 0.25 & -0.01 & 0.19 & 0.02 & 0.80 & 0.16 & 1.12 \\
\hline & $\mathrm{Fe}_{\mathrm{d}}$ & -0.20 & 0.58 & -0.25 & 0.70 & -0.19 & 0.20 & -0.28 & 0.10 \\
\hline \multirow{2}{*}{ Hsuperox $-\mathrm{H}_{2}-\mathrm{Cl}^{-}$} & $\mathrm{Fe}_{\mathrm{p}}$ & -0.15 & 0 & -0.13 & 0 & -0.11 & 0 & -0.01 & 0 \\
\hline & $\mathrm{Fe}_{\mathrm{d}}$ & -0.21 & 0 & -0.30 & 0 & 0.10 & 0 & -0.29 & 0 \\
\hline \multirow{2}{*}{ Hsuperox $-\mathrm{H}^{-} \mathrm{Cl}^{-}$} & $\mathrm{Fe}_{\mathrm{p}}$ & -0.11 & 0 & -0.09 & 0 & 0.00 & 0 & -0.02 & 0 \\
\hline & $\mathrm{Fe}_{\mathrm{d}}$ & -0.28 & 0 & -0.15 & 0 & -0.29 & 0 & -0.18 & 0 \\
\hline \multirow{2}{*}{$\begin{array}{l}\text { Hsupersuperox- } \\
\qquad \mathrm{H}^{-} \mathrm{Cl}^{-}\end{array}$} & $\mathrm{Fe}_{\mathrm{p}}$ & -0.12 & -0.01 & -0.12 & 0.36 & 0.01 & -0.04 & -0.03 & 0.40 \\
\hline & $F e_{d}$ & 0.06 & 0.95 & 0.03 & 0.56 & 0.16 & 1.21 & 0.11 & 0.51 \\
\hline
\end{tabular}

DFT functional. We used the pure $\mathrm{BP}^{2,3}$ and the hybrid $\mathrm{PBE} 0^{4}$ generalized gradient approximations (GGA) functionals that are popular in the modelling of $\mathrm{FeFe}$ hydrogenases properties and reactivity ${ }^{5-7}$. Here we considered the neutral arginine as $\mathrm{Cl}^{-}$ reference state and we adopted the implicit solvation with dielectric constant equal to 4 .

We compared the two functionals on the basis of optimized geometries, NBO atomic/spin charges and $\mathrm{Cl}^{-}$binding energies.

For each species considered, the optimized geometries are similar in particular regarding i) the position and coordination of the substrate $\left(\mathrm{H}_{2}, \mathrm{H}^{-}\right)$ii) the position and coordination of chloride. This fact is in line with the small differences in the BP86 and PBE0 electronic structures although the homo-lumo gap for hybrid is significantly lower than that computed with pure functionals. 
Author version of: J. Am. Chem. Soc. 1405485 (2018)

http://dx.doi.org/doi:10.1021/jacs.8b01414

The values of the $\mathrm{Cl}^{-}$binding energies can be easily divided into three groups that differ from relative $\mathrm{Cl}^{-}$binding energy with respect to Hox used as reference. These groups are:

1) small values with average $-0.9 \mathrm{kcal} / \mathrm{mol}$ for $\mathrm{BP} 86$ and $-0.3 \mathrm{kcal} / \mathrm{mol}$ for PBE0 (Hox, Hox- $\mathrm{H}_{2}$, Hsuperox- $\mathrm{H}^{-}$);

2) very low value of $27.2 \mathrm{kcal} / \mathrm{mol}$ for both $\mathrm{BP} 86$ and PBE0 $\left(\mathrm{Hox}-\mathrm{H}^{-}\right)$

3) very high values with average $-22.3 \mathrm{kcal} / \mathrm{mol}$ for BP86 and -21.4 for PBE0 (Hsuperox, Hsuperox- $\mathrm{H}_{2}$, Hsuspersuperox- $\mathrm{H}^{-}$).

Solvatation with implicit COSMO model and D3 dispersion correction. Implicit solvation can be taken into account by mean of the COSMO approach using a value of 4 for the dielectric constant inside the active site pocket. Gas phase computations underestimate the $\mathrm{Cl}^{-}$binding energies for the first group, on average, by $7.9 \mathrm{kcal} / \mathrm{mol}$. Large and negative or positive values are increased in their absolute values when implicit solvation is not considered. The gas phase computations are clearly less accurate and for this reason we consider only values computed with the COSMO approach.

The values computed with the Grimme D3 approach, to take into account the dispersion interactions, are on average only $1.2 \mathrm{kcal} / \mathrm{mol}$ more negative than those computed without considering the correction.

Reference state for free $\mathrm{Cl}^{-}$. The choice of the reference state of the $\mathrm{Cl}^{-}$anion is required to evaluate the $\mathrm{Cl}^{-}$bonding energies but it does not essentially influence the relative values. The basic idea is to consider a reference state in which a residue side chain coordinates the $\mathrm{Cl}^{-}$ion and then releases the ion to the $\mathrm{H}$-cluster. There is a large number of possibilities, according to the aminoacidic environment around the $\mathrm{H}$-cluster, although we are not simulating the $\mathrm{Cl}^{-}$coordination to $\mathrm{H}$-cluster but only looking for a reasonable protocol to compute $\mathrm{Cl}^{-}$binding energies.

We considered therefore

1) Arginine side chain in its neutral or positively charged form

2) Threonine side chain

The plot of the values in table S1 shows the effect of changing the $\mathrm{Cl}^{-}$reference state and/or the functional. 


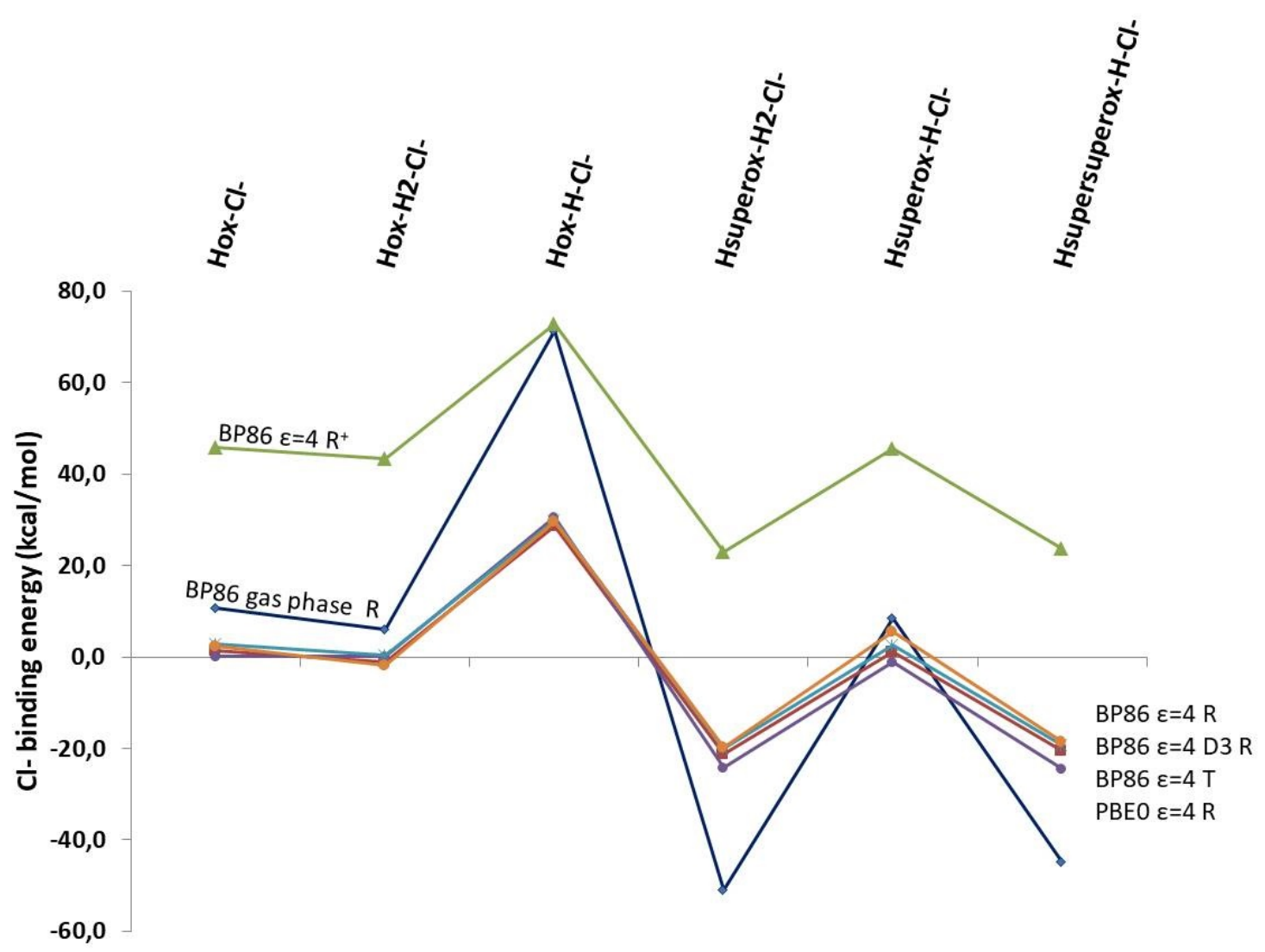

Except for gas phase computations, the values are almost equally shifted by a fixed energy that depends on the choice of the reference. When comparing $\mathrm{R}$ and $\mathrm{R}+$ as side chain for $\mathrm{Cl}^{-}$ reference state, $\mathrm{R}+$ binding energies are always shifted around $+44.3 \mathrm{kcal} / \mathrm{mol}$ compared those of R.

For neutral references ( $\mathrm{R}$ or $\mathrm{T}$ side chain) the average $\mathrm{Cl}^{-}$binding energies are reported in the table S4 below. In all the cases considered, their standard deviations are lower than 3.0 $\mathrm{kcal} / \mathrm{mol}$.

Table S4. Average $\mathrm{Cl}^{-}$binding energies (in $\mathrm{kcal} / \mathrm{mol}$ ) with their standard deviation computed from 4 values obtained using neutral reference state ( $R$ and $T$ side chains).

\begin{tabular}{|c|c|}
\hline & $<\mathrm{DE}> \pm \boldsymbol{\sigma}$ \\
\hline Hox $-\mathrm{Cl}^{-}$ & $1.7 \pm 1.2$ \\
\hline Hox $-\mathrm{H}_{2}-\mathrm{Cl}^{-}$ & $-1.0 \pm 1.0$ \\
\hline Hox- $-\mathrm{H}^{-} \mathrm{Cl}^{-}$ & $29.7 \pm 0.8$ \\
\hline Hsuperox $-\mathrm{H}_{2}-\mathrm{Cl}^{-}$ & $-21.3 \pm 2.1$ \\
\hline Hsuperox- $-\mathrm{H}^{-} \mathrm{Cl}^{-}$ & $2.0 \pm 2.8$ \\
\hline Hsupersuperox- $\mathrm{H}^{-} \mathrm{Cl}^{-}$ & $-20.7 \pm 2.7$ \\
\hline
\end{tabular}


The values in Table S4 show that the binding energies can be sorted into three groups, as discussed in the main text. The choice of a neutral reference state is more reasonable since the protein binding sites for halides are usually not charged.

\section{S7. Structural and electronic features of the main species computed at DFT level.}

In this section we describe in detail the main forms considered above at BP86/TZVP level with implicit COSMO solvent at $\varepsilon=4$.

At first, we need to identifiy the bond distance of the $\mathrm{Fe}(\mathrm{II})-\mathrm{Cl}^{-}$bond at BP86/TZVP level of theory.

1) Ferrous chloride tetrahydrate $\mathrm{FeCl}_{2}\left(\mathrm{H}_{2} \mathrm{O}\right)_{4}(\mathrm{Fe}-\mathrm{Cl}$ : $2.38 \AA$ according to the $\mathrm{X}$-ray structure ${ }^{8}$; DFT $2.343 \AA$ )

2) $\mathrm{T}_{\mathrm{d}}$ high-spin $\left[\mathrm{FeCl}_{4}\right]^{2-}$ anionic complex is $\left[\mathrm{N}\left(\mathrm{CH}_{3}\right)_{4}\right]_{2}\left[\mathrm{FeCl}_{4}\right](\mathrm{Fe}-\mathrm{Cl} 2.290 \AA$ according to the X-ray structure ${ }^{9}$; DFT $2.392 \AA$ )

These data suggest that a fully bound $\mathrm{Fe}(\mathrm{II})-\mathrm{Cl}^{-}$interaction is at least $2.39 \AA$ at $\mathrm{DFT}$ level.

It is possible before commenting the various forms, to assess a general statement regarding $\mathrm{Cl}^{-}$binding. This is favored in over oxidized forms (Hsuperox and Hsupersuperox forms) and with protonated $\mathrm{NH}_{2}^{+}(\mathrm{ADT})$, where we observe the formation of a charge-charge interaction. None of the Hox forms shows a significant $\mathrm{Cl}^{-}$binding.

Hox $\mathrm{Cl}^{-}$form. $\mathrm{Fe}(\mathrm{I}) \mathrm{Fe}(\mathrm{II}) \mathrm{Hox}$ state can bind $\mathrm{Cl}^{-}$at the distal $\mathrm{Fe}$ atom or at the $\mathrm{NH}$ of the ADT, with the formation in both cases of two electrostatic $\mathrm{Cl}^{-} \ldots \mathrm{H}$ interactions (with the $\mathrm{NH}$ of the ADT and with the SH of the Cys178)
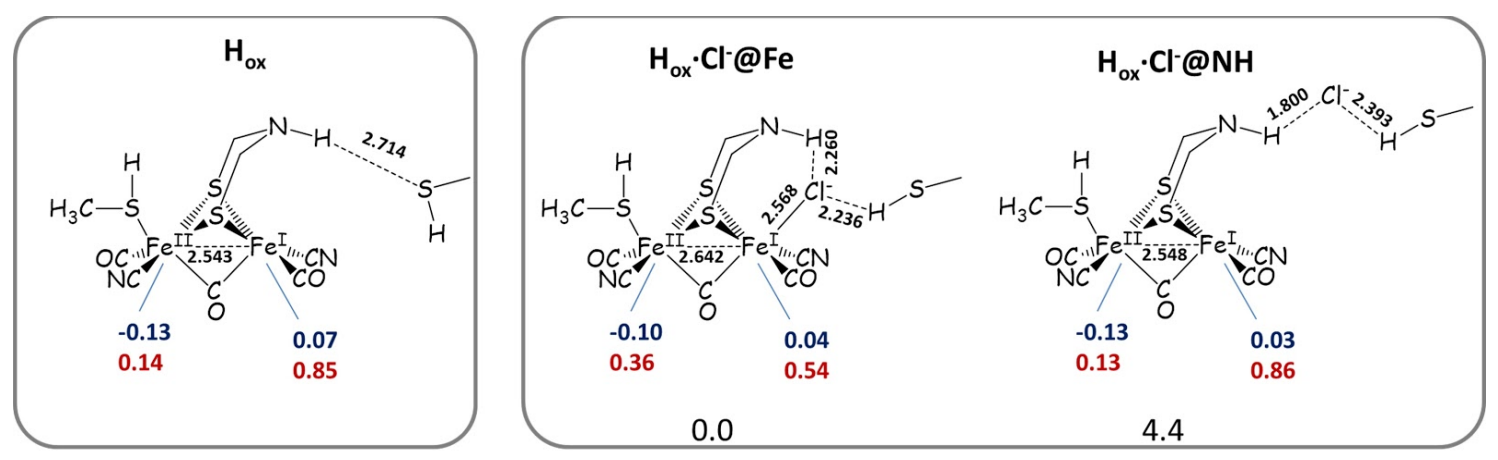

Figure S10. Hox and Hox $\mathrm{Cl}^{-}$bound forms. Relevant atomic distances in $\AA$, NBO atomic (blue) and spin (red)

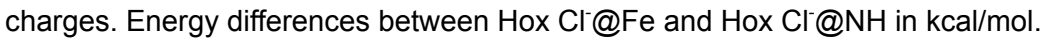

The two forms differ in energy by $4.4 \mathrm{kcal} / \mathrm{mol}$ in favor of the $\mathrm{Cl}^{-} \mathrm{Fe}_{\mathrm{d}}$ isomer. In this latter, the $\mathrm{Fe}-\mathrm{Fe}$ bond elongation of $0.094 \AA$ suggests a small bonding electron density transfer toward the interatomic $\mathrm{Fe}^{-\mathrm{Cl}^{-}}$region and the stabilization of $4.4 \mathrm{kcal} / \mathrm{mol}$ compared to $\mathrm{Cl}^{-} \mathrm{NH}$ isomer that this $\mathrm{Fe}^{-\mathrm{Cl}^{-}}$interaction (if any) is weak. This conclusion is also corroborated by the comparison between $\mathrm{Fe}-\mathrm{Cl}$ bond distance equal to $2.39 \AA$ that we consider as a fully bound interaction. 
Hox $\mathrm{H}_{2} \mathrm{Cl}^{-}$form. $\mathrm{Fe}(\mathrm{I}) \mathrm{Fe}(\mathrm{II}) \mathrm{Hox} \mathrm{H}_{2}$ form binds $\mathrm{Cl}^{-}$at the protonated $\mathrm{NH}_{2}^{+}$of the ADT, thus inducing the premature $\mathrm{H}_{2}$ splitting, as shown in the figure $\mathrm{S} 11$.

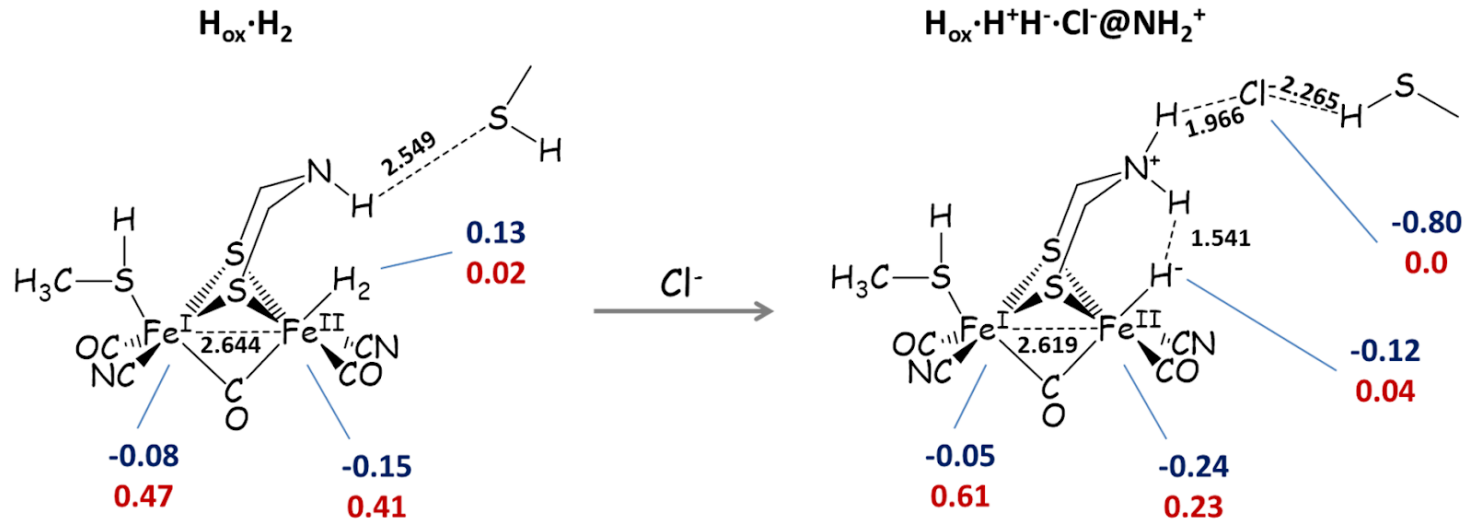

Figure S11. Hox $\mathrm{H}_{2}$ and $\mathrm{Hox} \mathrm{H}_{2} \mathrm{Cl}^{-}$bound forms. Relevant atomic distances in $\AA$, NBO atomic (blue) and spin (red) charges.

The atomic and spin charges for $\mathrm{Hox}-\mathrm{H}_{2}-\mathrm{Cl}^{-}$suggests a $\mathrm{Fe}(\mathrm{I}) \mathrm{Fe}(\mathrm{II})$ hydride form. The Hox $-\mathrm{H}_{2}-\mathrm{Cl}^{-}$form in which the $\mathrm{H}_{2}$ (see Figure S12) is not splitted, has $6.8 \mathrm{kcal} / \mathrm{mol}$ more than the $\mathrm{H}_{2}$ splitted form.

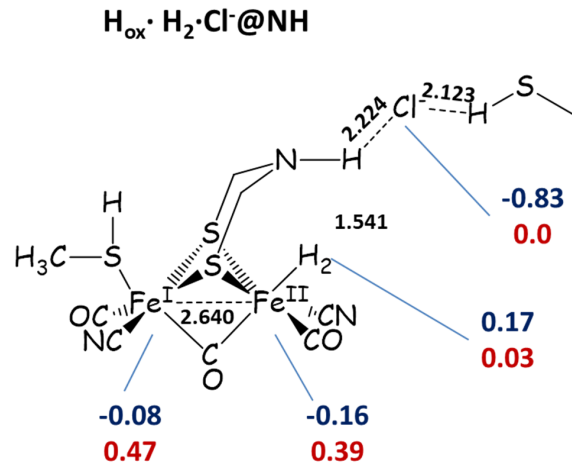

Figure S12. $\mathrm{Hox} \mathrm{H}_{2} \mathrm{Cl}^{-}$bound form in which $\mathrm{H}_{2}$ is not splitted. Relevant atomic distances in $\AA$, NBO atomic (blue) and spin (red) charges. 
Hox $\mathrm{H}^{-} \mathrm{Cl}^{-}$forms. The $\mathrm{HoxH}^{-}$form is in a $\mathrm{Fe}(\mathrm{I}) \mathrm{Fe}(\mathrm{II})$ redox state with the hydride at the $\mathrm{Fe}_{\mathrm{d}}$ (see figure S13).

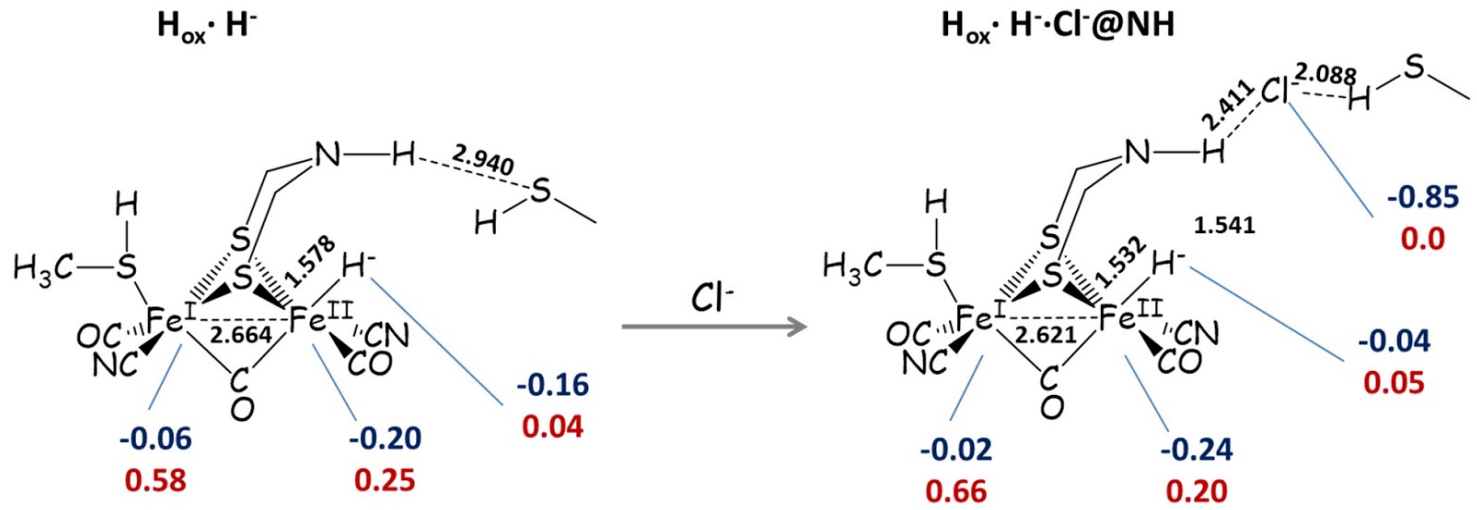

Figure S13. Hox $\mathrm{H}^{-}$and $\mathrm{Hox} \mathrm{H}^{-} \mathrm{Cl}^{-}$forms. Relevant atomic distances in $\AA$, NBO atomic (blue) and spin (red) charges.

The $\mathrm{Cl}^{-}$binding to $\mathrm{HoxH}^{-}$occurs at the amine of the ADT yielding again a $\mathrm{Fe}(\mathrm{I}) \mathrm{Fe}(\mathrm{II})$ form.

Hsuperox $\mathrm{H}_{2} \mathrm{Cl}^{-}$forms. In Hsuperox $\mathrm{H}_{2}$ form, the hydrogen molecule is splitted unlike in Hox $\mathrm{H}_{2}$. The electronic structure according to $\mathrm{NBO}$ charges is compatible with a $\mathrm{Fe}(\mathrm{I}) \mathrm{Fe}(\mathrm{I}) \mathrm{H}^{+}$ form. The NBO charges of Hox $\mathrm{H}_{2}$ shows that most of the oxidation in Hsuperox $\mathrm{H}_{2}$ is due to the three $\mathrm{S}$ atoms (the Hsuperox-Hox $\Delta \mathrm{q}$ equal to +0.5 electrons). The Hsuperox $\mathrm{H}_{2}$ form in which $\mathrm{H}_{2}$ is not splitted is a local minimum $13.9 \mathrm{kcal} / \mathrm{mol}$ higher in energy than the $\mathrm{H}_{2}$ splitted form.

$\mathrm{Cl}^{-}$binding to Hsuperox $\mathrm{H}_{2}$ is essentially identical to that of $\mathrm{Hox}_{2} \mathrm{Cl}^{-}$form (see Figure S14)

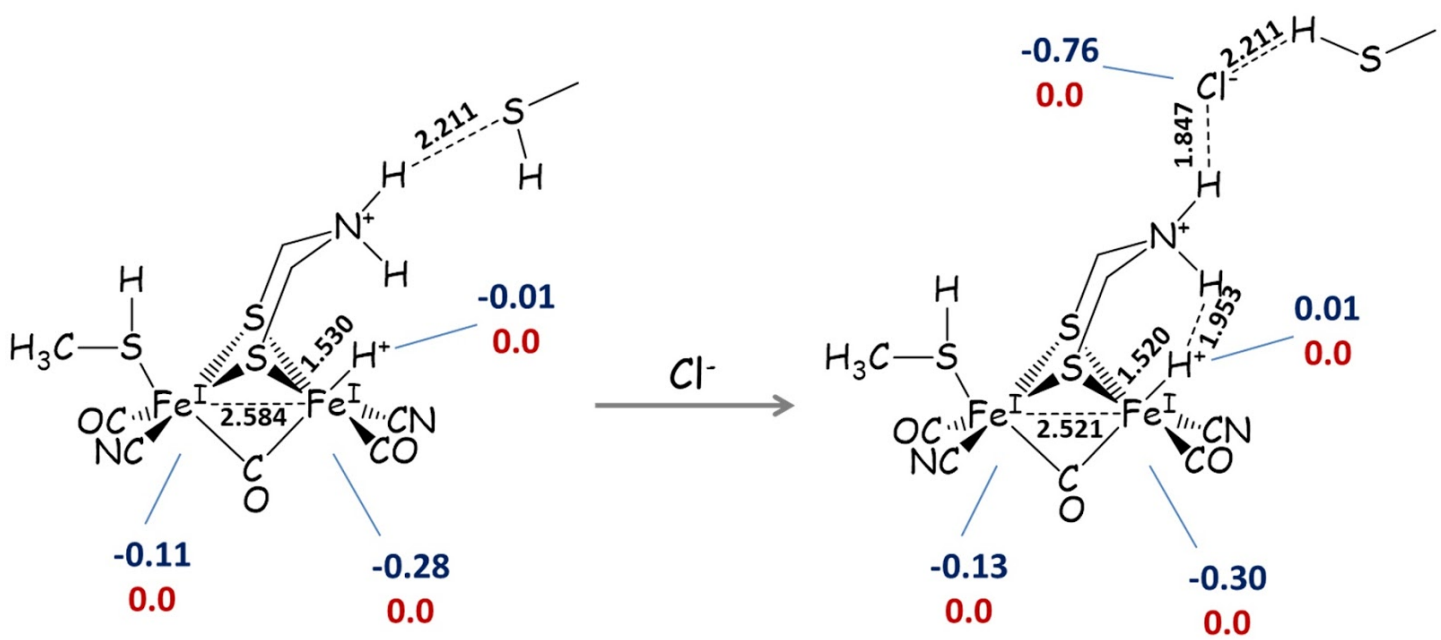

Figure S14. Hsuperox $\mathrm{H}_{2}$ and Hsuperox $\mathrm{H}_{2} \mathrm{Cl}^{-}$forms. Relevant atomic distances in $\AA$, NBO atomic (blue) and spin (red) charges.

According to the NBO charges, the redox state is again $\mathrm{Fe}(\mathrm{I}) \mathrm{Fe}(\mathrm{I})$. 
Hsuperox $\mathrm{H}^{-} \mathrm{Cl}^{-}$forms. Hsuperox $\mathrm{H}^{-}$form is in a $\mathrm{Fe}(\mathrm{l}) \mathrm{Fe}(\mathrm{I}) \mathrm{Hred}$ redox with the $\mathrm{H}$ atom bound at $\mathrm{Fe}_{\mathrm{d}}$ with $\mathrm{Fe}-\mathrm{H}$ distance equal to $1.515 \AA$. The protonated Hred isomer is slightly higher in energy by $7.6 \mathrm{kcal} / \mathrm{mol}$ (see Figure S15) and features the $\mathrm{Fe}_{\mathrm{d}}$ ligands rotation (equatorial $\mathrm{CO}$ is in apical position and the the bridging $\mathrm{CO}$ in equatorial position).
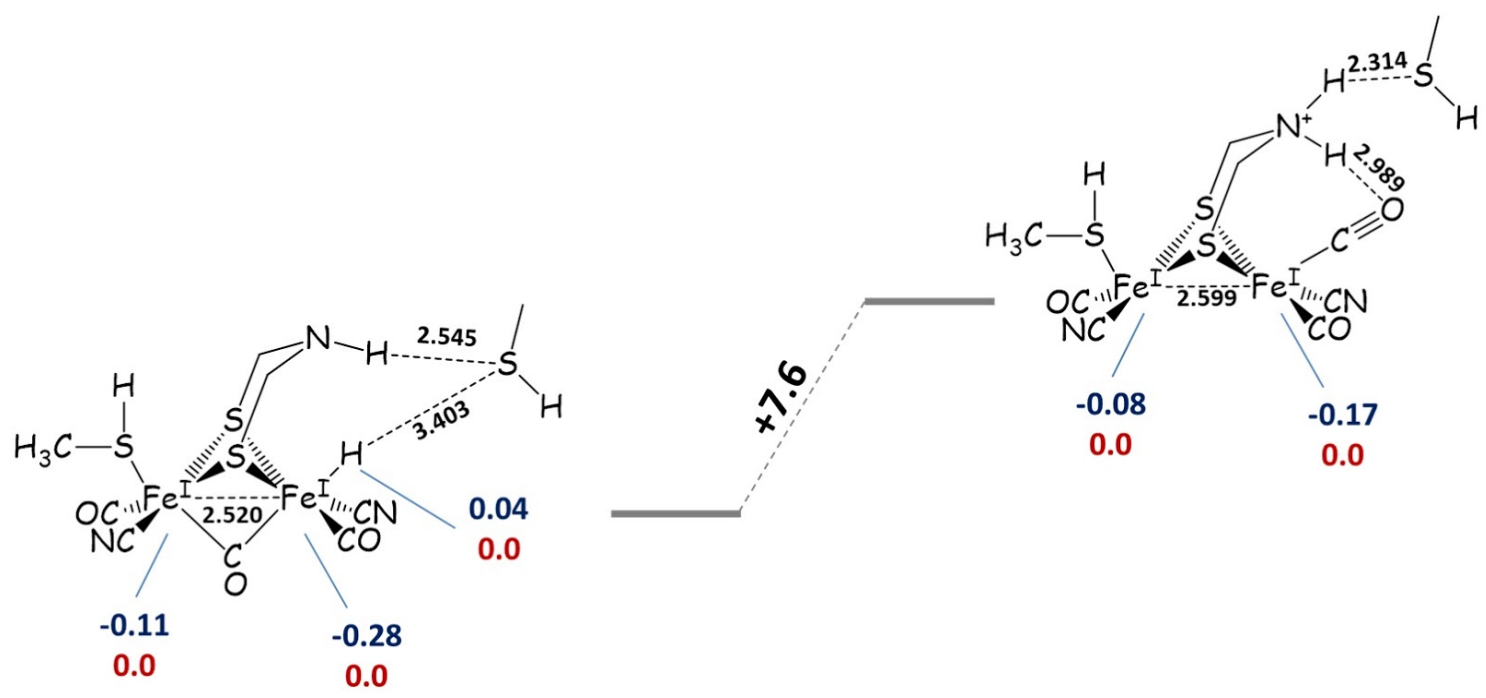

Figure S15. Hsuperox $\mathrm{H}^{-}$isomers. Relevant atomic distances in $\AA$, NBO atomic (blue) and spin (red) charges.

Upon $\mathrm{Cl}^{-}$binding at the protonated $\mathrm{NH}_{2}^{+}$of the ADT, the geometry optimization first converged to a transient $\mathrm{Hred} \mathrm{Fe}(\mathrm{I}) \mathrm{Fe}(\mathrm{I})$ protonated form with the typical H-cluster up-side down diiron coordination, and then to the corresponding all terminal ligand form, in which the bridged $\mathrm{CO}$ ligand is in apical position on the $\mathrm{Fe}_{\mathrm{d}}$ (see Figure S16). 


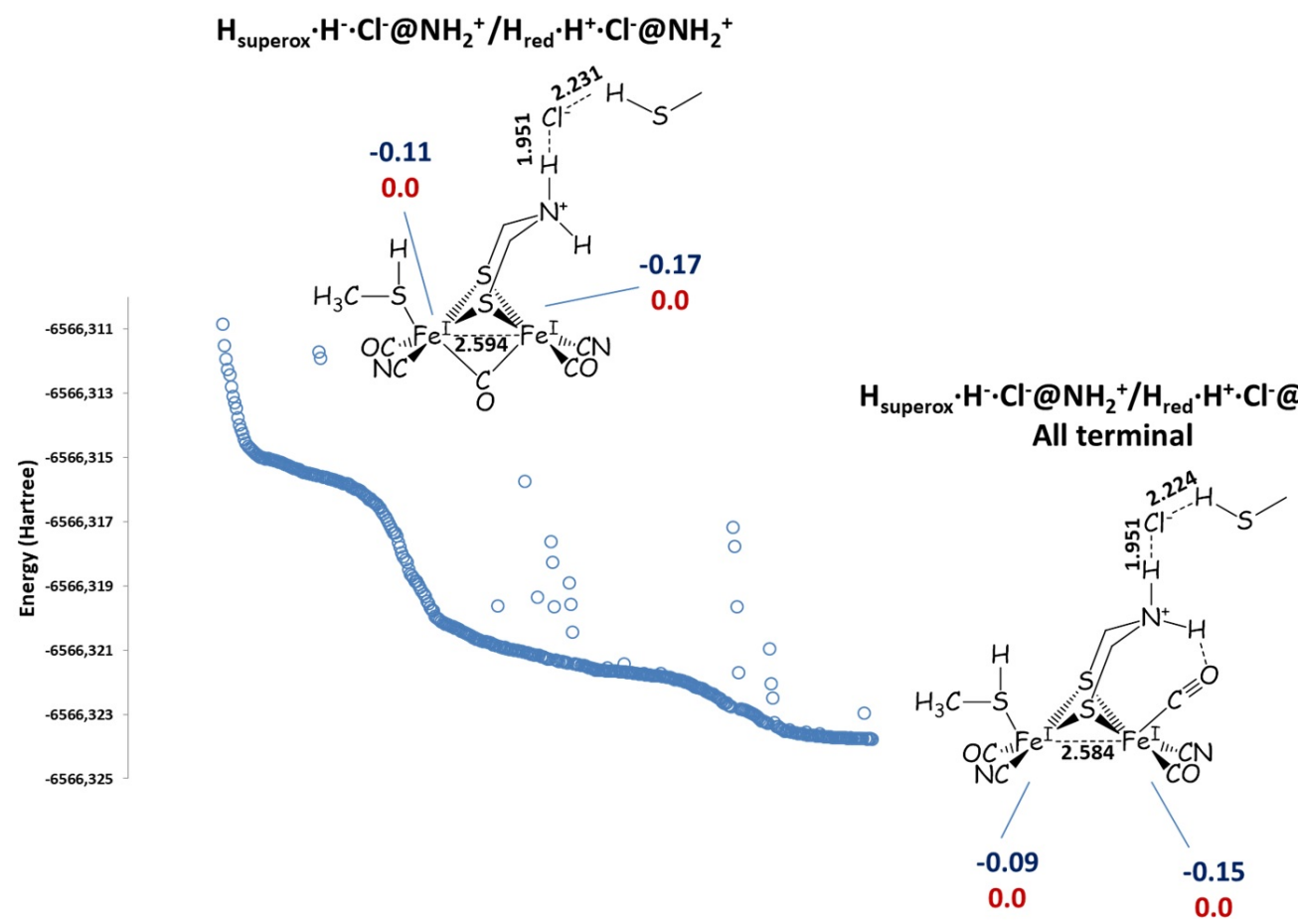

Figure S16. Hsuperox-H-Cl- DFT optimization history. The total energy is reported in Hartree. Relevant atomic distances in $\AA$, NBO atomic (blue) and spin (red) charges.

Hsuperosuperx $\mathbf{H}$ - Cl- form. Formally these $\mathrm{Fe}(\mathrm{III}) \mathrm{Fe}(\mathrm{II})$ forms can be obtained from further 1 electron oxidation of $\mathrm{Fe}(\mathrm{II}) \mathrm{Fe}(\mathrm{II})$ corresponding forms. Hsupersuperox $\mathrm{H}^{-}$can be described as the Hox protonated form. This form binds $\mathrm{Cl}^{-}$at $\mathrm{Fe}_{\mathrm{d}}$ (see Figure S17) and its redox state is compatible with a $\mathrm{Fe}(\mathrm{I} / \mathrm{II}) \mathrm{Fe}(\mathrm{I} / \mathrm{II})$ state, in which we consider both $\mathrm{Fe}$ atoms as intermediate between $\mathrm{Fe}(\mathrm{I})$ and ferrous state. The isomer in which $\mathrm{Cl}^{-}$is bound at $\mathrm{NH}_{2}{ }^{+}$is higher in energy by $2.8 \mathrm{kcal} / \mathrm{mol}$ than the isomer with chloride bound to the $\mathrm{Fe}_{\mathrm{d}}$.

$$
\mathrm{H}_{\text {supersuperox }} \cdot \mathrm{H}^{-} / \mathrm{H}_{\mathrm{ox}} \cdot \mathrm{H}^{+}
$$

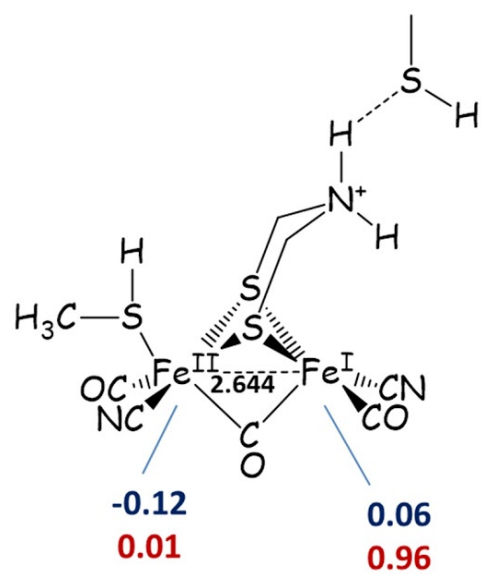

\section{$\mathrm{H}_{\mathrm{ox}} \cdot \mathrm{H}^{+} \cdot \mathrm{Cl}^{-} @ \mathrm{Fe}$}

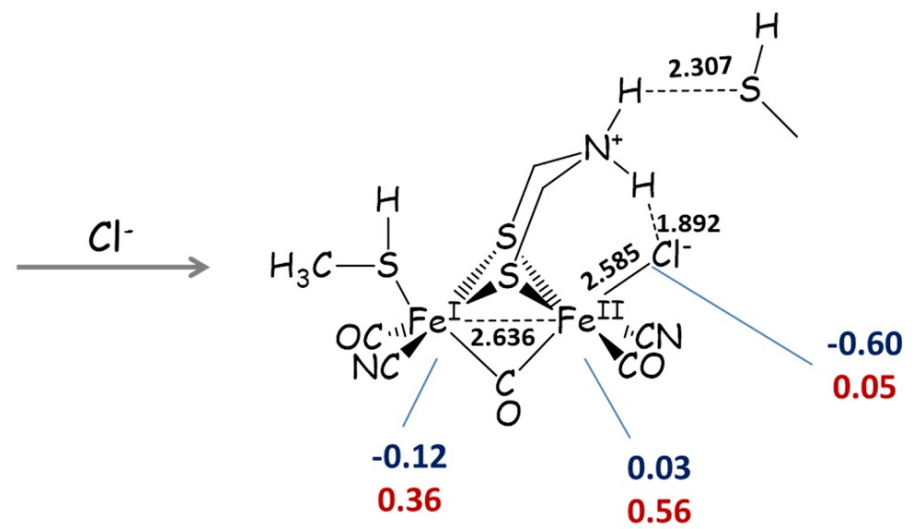

Figure S17. Hsupersuperox $\mathrm{H}^{-}$and Hsupersuperox $\mathrm{H}^{-} \mathrm{Cl}^{-}$forms. Relevant atomic distances in $\AA$, NBO atomic (blue) and spin (red) charges. 
Hsuperox $\mathrm{Cl}^{-}$form. $\mathrm{Fe}(\mathrm{II}) \mathrm{Fe}(\mathrm{II})$ Hsuperox form (Fe-Fe bond distance $2.510 \AA$ ) binds $\mathrm{Cl}^{-}$at $\mathrm{Fe}_{\mathrm{d}}$ (see Figure S18).
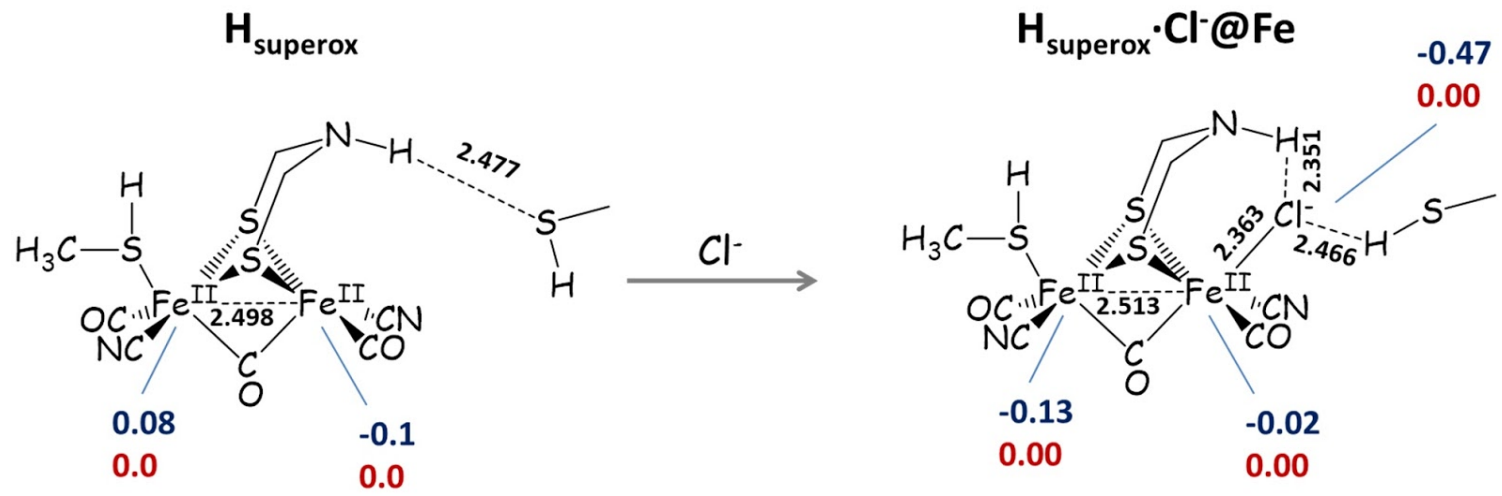

Figure S18. Hsuperox $\mathrm{Cl}^{-}$forms. Relevant atomic distances in $\AA$, NBO atomic (blue) and spin (red) charges.

This $\mathrm{Fe}-\mathrm{Cl}^{-}$distance of $2.363 \AA$ is close to that found at the same level of theory as reference for a fully bound $\mathrm{Fe}-\mathrm{Cl}^{-}$interaction $(2.39 \AA)$, suggesting that in this case the $\mathrm{Cl}^{-}$ion actually forms a chemical bond with $\mathrm{Fe}(\mathrm{II})$. Among all the structures considered in this paper, only this clearly presents a strong $\mathrm{Fe}(\mathrm{II})-\mathrm{Cl}^{-}$interaction.

\section{S8. Computations using a $\mathrm{Fe}_{4} \mathrm{~S}_{4}-\mathrm{Fe}_{2} \mathrm{~S}_{2}$ model}

The possible role of the cubane in the $\mathrm{Cl}^{-}$binding has been investigated in the case of Hox $\mathrm{H}_{2} \mathrm{Cl}^{-}$and Hsuperox $\mathrm{H}_{2} \mathrm{Cl}^{-}$. Here the main aspect is to understand if $\mathrm{Cl}^{-}$is able to induce any $\mathrm{Fe}_{2} \mathrm{~S}_{2} / \mathrm{Fe}_{4} \mathrm{~S}_{4}$ charge transfer. In the figure $\mathrm{S} 19$ below structures and NBO atomic and spin charges are compared. No CT is observed in the 6Fe models and the redox state of the $\mathrm{Fe}_{2} \mathrm{~S}_{2}$ binuclear sub-cluster is preserved. 

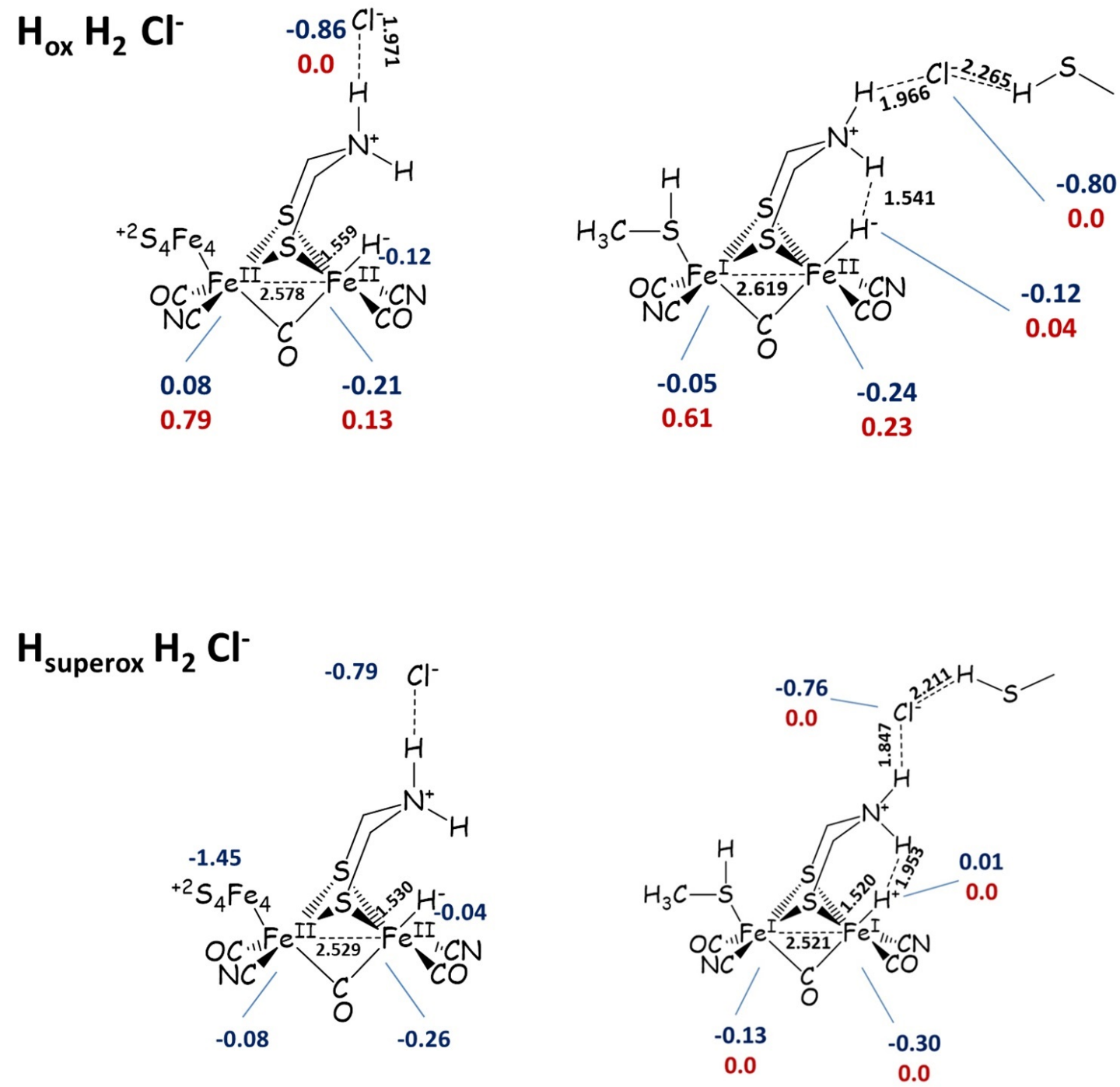

Figure S19. 2Fe (right) or 6Fe (left) $\mathrm{Hox}_{2} \mathrm{Cl}^{-}$and Hsuperox $\mathrm{H}_{2} \mathrm{Cl}^{-}$model forms Relevant atomic distances in $\AA$, NBO atomic (blue) and spin (red) charges.

\section{References}

(1) Peters, J. W.; Lanzilotta, W. N.; Lemon, B. J.; Seefeldt, L. C. Science 1998, 282, 1853.

(2) Becke, A. D. Phys. Rev. A 1988, 38, 3098.

(3) Perdew, J. P.; Yue, W. Phys. Rev. B: Condens. Matter Mater. Phys. 1986, 33, 8800.

(4) Adamo, C.; Scuseria, G. E.; Barone, V. J. Chem. Phys. 1999, 111, 2889.

(5) Liu, C.; Liu, T.; Hall, M. B. J. Chem. Theory Comput. 2015, 11, 205.

(6) Bertini, L.; Bruschi, M.; de Gioia, L.; Fantucci, P.; Greco, C.; Zampella, G. In Atomistic Approaches in Modern Biology; Reiher M., Eds; Topics in Current Chemistry; Springer, Berlin, Heidelberg, 2006; vol 268, pp 1-46.

(7) Bertini, L.; Bruschi, M.; Cosentino, U.; Greco, C.; Moro, G.; Zampella, G.; De Gioia, L. Methods Mol. Biol. 2014, 1122, 207.

(8) Penfold, B. R.; Grigor, J. A. Acta Crystallogr. 1959, 12, 850.

(9) Lauher, J. W.; Ibers, J. A. Inorg. Chem. 1975, 14, 348. 